\title{
1 Class A GPCRs use the membrane potential to increase their sensitivity
} 2 and selectivity

3

4

Daria N. Shalaeva ${ }^{1,2}$, Dmitry A. Cherepanov ${ }^{2,4}$, Michael Y. Galperin ${ }^{5}$, Gert Vriend ${ }^{6}$ and Armen Y. Mulkidjanian ${ }^{1,2,3 *}$

${ }^{1}$ School of Physics, Osnabrück University, 49069, Osnabrück, Germany; ${ }^{2}$ A.N. Belozersky Institute of Physico-Chemical Biology and ${ }^{3}$ School of Bioengineering and Bioinformatics, Lomonosov Moscow State University, Moscow 117999, Russia; ${ }^{4}$ N.N. Semenov Institute of Chemical Physics, Russian Academy of Sciences, 119991 Moscow, Russia; ${ }^{5}$ National Center for Biotechnology Information, National Library of Medicine, National Institutes of Health, Bethesda, Maryland 20894, USA; ${ }^{6}$ Centre for Molecular and Biomolecular Informatics, Radboud University Medical Centre, 6525 HP Nijmegen, The Netherlands

*Corresponding author: Armen Y. Mulkidjanian, School of Physics, Osnabrück University, 49069, Osnabrück, Germany, E-mail: amulkid@uni-osnabrueck.de

\section{Author E-mails:}

Daria N. Shalaeva,dshalaeva@uni-osnabrueck.de

Dmitry A. Cherepanov, cherepanov@belozersky.msu.ru

$$
\text { Michael Y. Galperin, galperin@nih.gov }
$$

Gert Vriend, vriendgert@ gmail.com

5 Abbreviations

6 cAMP, 3'-5'-cyclic adenosine monophosphate; GPCR, G-protein coupled receptor, MR, microbial 7 rhodopsin, RMSD, root-mean-square deviation; TM, transmembrane, NR - Na-translocating microbial 8 rhodopsin, ChR2 - channelrhodopsin 2. 


\section{Abstract}

31 The human genome contains about 700 genes of $\mathrm{G}$ protein-coupled receptors (GPCRs) of class A; these seven-helical membrane proteins are the targets of almost half of all known drugs. In the middle of the helix bundle, crystal structures revealed a highly conserved sodium-binding site, which is connected with the extracellular side by a water-filled tunnel. Sodium ions are observed in GPCRs crystallized in their inactive conformations, but not in GPCRs that were trapped in agonist-bound active conformations. The escape route of the sodium ion upon the inactive-to-active transition and its very direction, either into the cytoplasm or back outside the cell, hitherto remained obscure. We modeled sodium-binding GPCRs as electrogenic carriers of sodium ions. In this model the sodium gradient over the cell membrane would increase the sensitivity of GPCRs if their activation is thermodynamically coupled to the translocation of the sodium ion into the cytoplasm, while

42 decreasing it if the sodium ion retreats into the extracellular space upon receptor activation.

43 The model quantitatively describes the available data on both activation and suppression of distinct GPCRs by membrane voltage. The model also predicts selective amplification of the signal from (endogenous) agonists if only they, but not their (partial) analogs, could induce sodium translocation. Comparative structure and sequence analyses of sodium-binding GPCRs indicate a key role for the conserved leucine residue in the second transmembrane helix (Leu2.46) in coupling sodium translocation to receptor activation. Hence, class A

49 GPCRs appear to utilize the energy of the transmembrane sodium potential to increase their sensitivity and selectivity. 


\section{Introduction}

54 G-protein coupled receptors (GPCRs) are integral membrane proteins that consist of seven transmembrane (TM) helices surrounding a relatively polar core [1-4] (Fig. 1A-C). In most GPCRs, binding of the endogenous ligand (agonist) by the "inactive" form of protein causes a conformational change of the helical bundle (Fig. 1). The activated GPCR interacts with a G protein, which then triggers the intracellular signaling cascade. GPCRs are divided into several classes: rhodopsin-like receptors (class A), secretin receptors (class B), glutamate receptors (class C), fungal mating pheromone receptors (class D), cAMP receptors (class E), and frizzled receptors (class F). Sequence and structure comparisons of GPCRs support the notion that most, if not all, of them have a common evolutionary origin [5-7].

GPCRs are widespread among eukaryotes and are intensively studied for their ability to regulate various cellular processes. Different classes of GPCRs are unevenly represented in sequenced genomes from various eukaryotic lineages. In humans, class A GPCRs are the largest protein family with about 700 genes, whereas all other classes of GPCRs together have only about 150 representatives [6]. Human GPCRs serve as targets for about half of all known drugs [1].

The recent avalanche of high-resolution X-ray structures of GPCRs in ligand-free, agonistbound, and antagonist-bound forms revealed many important features of their functioning [4, 8-16]. The major feature is that activation of GPCRs is associated with a large displacement of the cytoplasmic half of helix 6. A conserved Trp residue in the middle of this helix (Trp6.48 according to the Ballesteros-Weinstein numeration for class A GPCRs as modified by Isberg et al. [17, 18], used hereafter) serves as the pivot of this motion, see Fig. 1C and [2, 9, 19-25]. Another feature uncovered by these structures was the presence of $\mathrm{Na}^{+}$ions in the vicinity of the ligand-binding sites in several class A GPCRs [12, 15, 16, 26-28]. The $\mathrm{Na}^{+}$ binding site is connected to the extracellular side through a clearly visible tunnel, but separated from the cytoplasmic side by a cluster of hydrophobic residues (Fig. 1A, B and [25, 26]). Analysis of the crystal structures of GPCRs in the active state (bound with agonists) shows that the $\mathrm{Na}^{+}$-binding pocket collapses from $\sim 200$ to $70 \AA^{3}$ due to the movements of TM helices upon activation [26]. There is no space for the $\mathrm{Na}^{+}$ion in the active state, suggesting that it leaves the receptor upon activation [12]. 
A
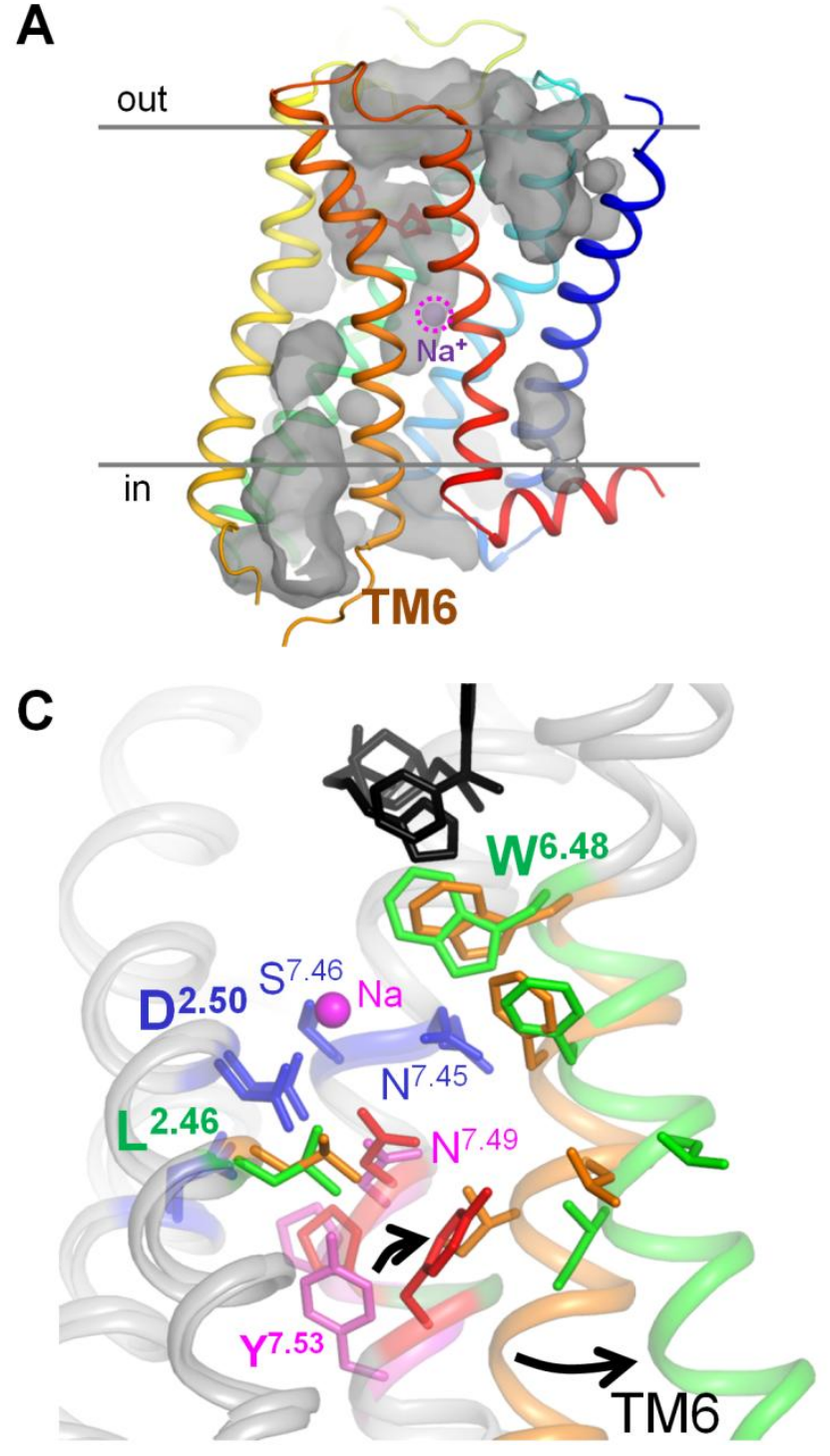

B

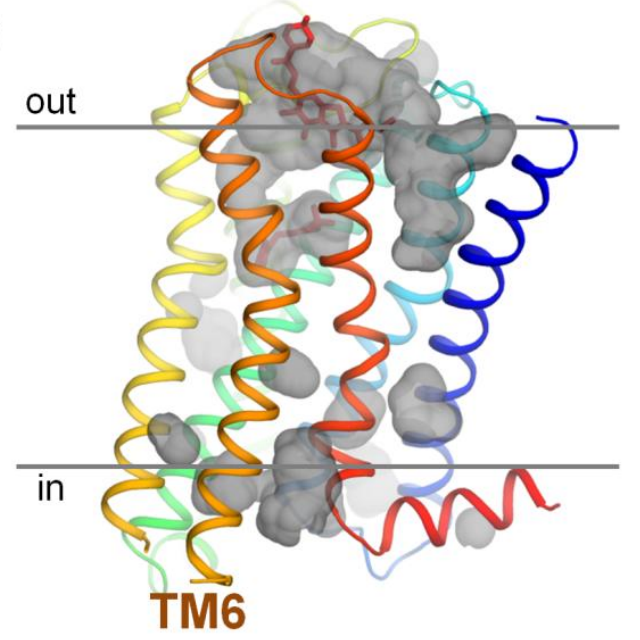

D

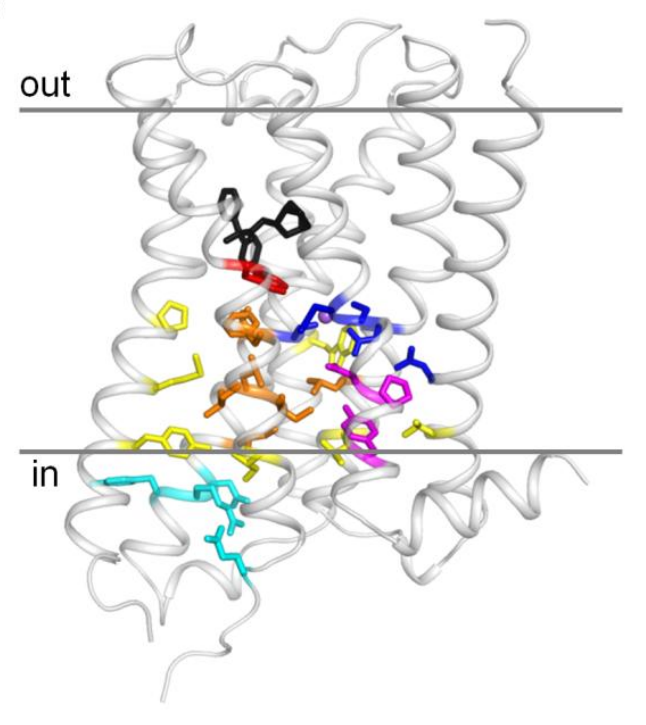

Fig. 1. Active and inactive conformations of GPCRs. A, B, conformations of the muscarinic acetylcholine receptor $\mathrm{M}_{2}$ in the in the inactive state (A, PDB 3UON [14]) and active state (B, PDB 4MQT [13]) with cavities shown; the lines indicate the boundaries of the membrane hydrophobic layer as taken from OPM database [29], "out" indicates the extracellular side, "in" indicates the cytoplasmic side. C. Superposition of the structures of $\mathrm{M}_{2}$ receptor in the inactive state ( the first layer of hydrophobic residues around the $\mathrm{Na}^{+}$-binding site colored ochre and residues of the NPxxY motif colored magenta) and in the active state ( the first layer of hydrophobic residues around the $\mathrm{Na}^{+}-$ binding site colored green and residues of the NPxxY motif colored red). The protein is shown as a gray cartoon, the agonist LY2119620 and antagonist 3-quinuclidinyl-benzilate are in black, $\mathrm{Na}^{+}-$ coordinating residues are colored dark blue. D, Overall location of the conserved motifs and hydrophobic residue clusters in GPCRs, shown on the structure of $\mathrm{M}_{2}$ receptor in the inactive state (PDB 3UON). The Trp6.48 residue is colored red, the second layer of hydrophobic residues is colored yellow, the residues of the DRY motif and the ionic lock are in light blue. Otherwise the color code as on panel C. 
99 The $\mathrm{Na}^{+}$binding residues are highly conserved among class A GPCRs [26, 28], indicating 100 that the $\mathrm{Na}^{+}$ion must be functionally important. Indeed, replacement of the key $\mathrm{Na}^{+}$-binding 101 Asp2.50 residue in helix 2 (see Fig. 1) facilitates binding of agonists by increasing the 102 association constants by 2-3 orders of magnitude in many, albeit not all, cases [26, 28, 30-

103 32]. In many cases, $\mathrm{Na}^{+}$depletion increased the basal activity of the respective receptor in the 104 absence of an agonist, suggesting that the $\mathrm{Na}^{+}$ion stabilizes the inactive state of the receptor $105[26,30,32,33]$. This interpretation is consistent with the structural data that show that the $106 \mathrm{Na}^{+}$ion is not observed in GPCRs in an active conformation [13, 26, 28, 34, 35].

107 Several years ago, Katritch and colleagues made a seminal suggestion that the $\mathrm{Na}^{+}$ion does 108 not return into the extracellular medium but instead gets released into the cytoplasm upon 109 GPCR activation [26]. The suggested mechanism, however, would require a transient 110 opening of a conduit for the $\mathrm{Na}^{+}$ion. Although the available structures of activated, $\mathrm{Na}^{+}-$ 111 lacking GPCRs [13, 34, 35] show no such a conduit, several computer simulations indicated a 112 possibility of a transient water-filled channel connecting the $\mathrm{Na}^{+}$-binding site with the 113 cytoplasm [24, 36, 37]. The proposed ability for the $\mathrm{Na}^{+}$ion to traverse the GPCR molecule 114 is also supported by the structural similarity between GPCRs and $\mathrm{Na}^{+}$-translocating bacterial 115 rhodopsins (Fig. S1), which suggests their common origin [7] and a common ability to 116 translocate the $\mathrm{Na}^{+}$ion.

117 Since the cytoplasm is negatively charged relatively to the extracellular medium, transfer of 118 the $\mathrm{Na}^{+}$cation into the cell could give an energy boost for the GPCR activation [26]. 119 Depolarization of the membrane would thus prevent the GPCR activation. This kind of 120 behavior has been, indeed, observed with many GPCRs. Still, some GPCRs, by contrast, were activated by depolarization, whereas some others were insensitive to it; see $[38,39]$ for reviews. Hence, the relation between the transmembrane gradient of sodium ions and GPCR activation deserves further clarification.

124 Unfortunately, the anticipated translocation of only one $\mathrm{Na}^{+}$ion per activation event 125 translates into a very weak electric current, which hampers the experimental tracking of this 126 process. In the absence of direct experimental data on the $\mathrm{Na}^{+}$ion translocation, we have 127 addressed it through modeling and comparative structural analyses.

128 Building on their similarity with $\mathrm{Na}^{+}$-translocating microbial rhodopsins, we modeled class $\mathrm{A}$ 129 GPCRs as facultative sodium carriers. The model implies that the bound $\mathrm{Na}^{+}$ion, upon 130 activation, can either slip in into the cytoplasm via a transiently opened passage (the carrier- 
131 on mode) or return to the extracellular side (the carrier-off mode). Just by varying the

132 dissociation constants for the agonist and the sodium ion, our model quantitatively describes

133 the available data on both activation and suppression of GPCRs by membrane voltage. In

134 addition, by combining evolutionary analyses with structural comparisons of GPCRs, we

135 have identified the strictly conserved leucine residue in the second transmembrane helix

136 (Leu2.46 in class A GPCRs) as the key player in coupling sodium translocation to receptor 137 activation.

138 In summary, this study proposes a mechanism that links GPCR activation, via $\mathrm{Na}^{+}$ 139 translocation, with the energy of membrane potential thereby offering an explanation for the 140 high sensitivity and selectivity of class A GPCRs.

142 Results

\section{1. Modeling $\mathrm{Na}^{+}$translocation in GPCRs}

144 We developed a model of GPCR activation that is analogous to earlier approaches to 145 modeling energy-converting enzymes [40] and GPCRs [41-44] but takes into account the 146 possibility of electrogenic translocation of a single $\mathrm{Na}^{+}$ion by a GCR concomitantly with its 147 activation.

148 The model considers a GPCR ensemble large enough for thermodynamic modeling. Each 149 receptor exists in a steady state balance between its active and inactive states; agonists shift 150 the distribution towards the active state, whereas $\mathrm{Na}^{+}$binding stabilizes the inactive state 151 (Fig. 2A). Both the inactive and active states were shown to exist as series of fast exchanging 152 conformation sub-states [2, 45-47]; for simplicity, we do not consider these sub-states in the 153 model. Also for simplicity it is just assumed that an activated GPCR triggers the signaling 154 cascade; the interaction of the active state with any other component (G-protein or arrestin) is not modeled. The model includes three binary transitions: (i) activation of the receptor, (ii) binding of the $\mathrm{Na}^{+}$ion, and (iii) binding of a signaling molecule (e.g. an agonist). These three transitions can be presented as a cubic graph with 8 separate states (Fig. 2B). Each of the

158 transitions is determined by its equilibrium constant: the receptor activation constant $\mathrm{L}$, the

$159 \mathrm{Na}^{+}$association constant $\mathrm{M}$, and the agonist association constant $\mathrm{N}$ (Table 1).

160 As shown in Fig. 2A, a GPCR has two operation modes: in the carrier-on mode (mode 1), the $161 \mathrm{Na}^{+}$-binding site can communicate with the cytoplasm, whereas in the carrier-off mode 
162 (mode 2), the $\mathrm{Na}^{+}$-binding site communicates only with the extracellular side. If the receptor operates in the carrier-off mode, all its eight states are in a thermodynamic equilibrium, and we can apply to them the principle of detailed balance (the forward and backward rates of transitions match each other). If the GPCR can translocate a $\mathrm{Na}^{+}$ion across the membrane

166 (carrier-on mode), then, under conditions of a nonzero transmembrane electrochemical 167 sodium potential difference (sodium gradient), the slowest transitions in Fig. 2B are not in 168 equilibrium (the forward and backward rates of these transitions do not match each other).

169 Our model assumes that the rate-limiting step is the slow "activating" conformational 170 transition from the $\mathrm{R}$ state to the final $\mathrm{R}^{*}$ state [44]. The ligand binding to the initial encounter state $\mathrm{R}$, binding/release of the $\mathrm{Na}^{+}$ion, and conformational transitions within inactive and active states are considered rapid as compared to the $\mathrm{R}$ to $\mathrm{R}^{*}$ transition, which

173 appears to be coupled with the pivotal movement of helix 6 in most class A GPCRs [2, 9, 19-

174 25]. In the case of opsin, the pivotal movement occurred slower than at $10^{-4} \mathrm{~s}$ with the 175 activation energy as high as $60 \mathrm{~kJ} / \mathrm{mol}[20,48]$. The slowness of the transition was also 176 confirmed by NMR data [22,46]. The assumption of the slow activating transition is in agreement with both the induced-fit model [43, 44, 47] and the conformational selection model [46]; these two models appear to describe the operation of most GPCRs. Then, at equilibrium, receptor activation is determined by the changes in the free energy of particular

180 states and can be described using the principle of detailed balance, according to which each

181 elementary process should be equilibrated by its reverse process at equilibrium. Since

182 activation of the receptor is much slower than any other transitions in the model, the detailed

183 balance principle can be applied separately to all inactive and all active receptor states (the left-hand and right-hand sides of the cubic diagram in Fig. 2B, respectively). 
A

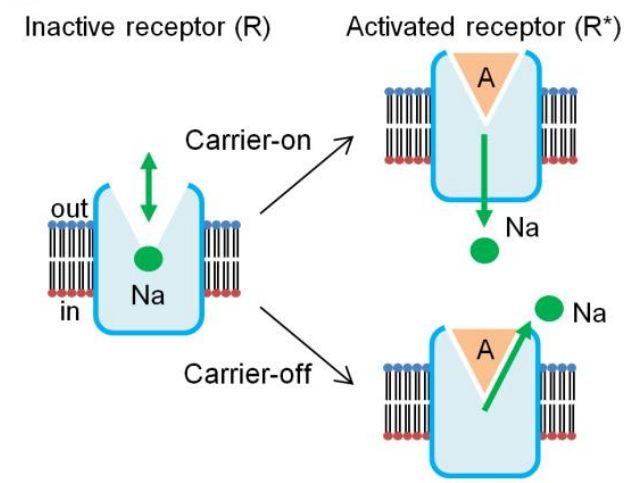

C

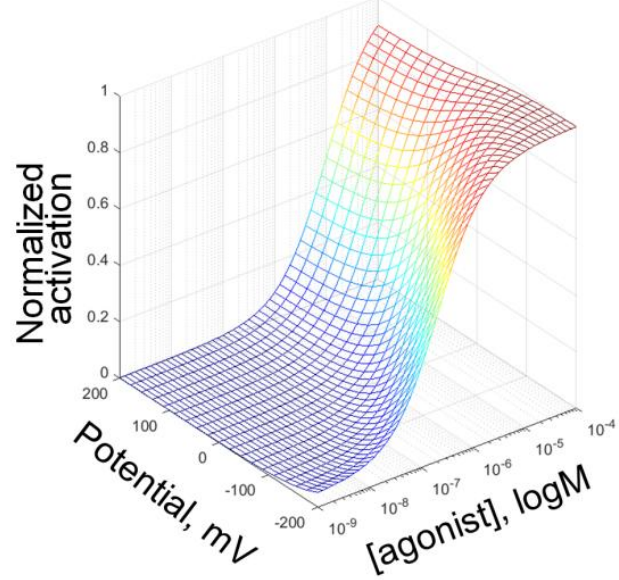

$\mathbf{E}$
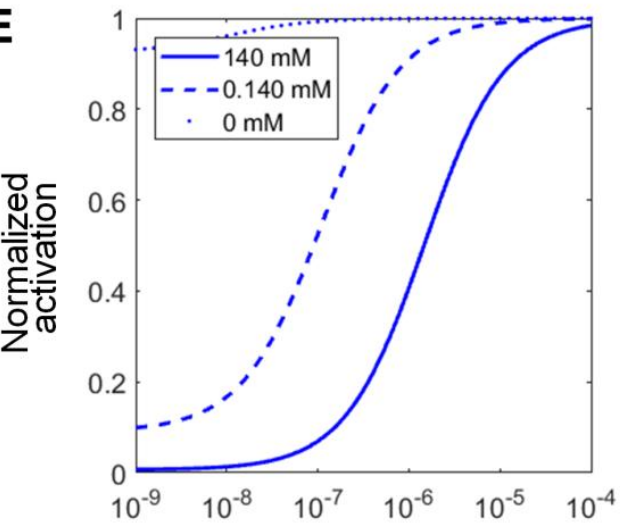

[agonist], log M
B

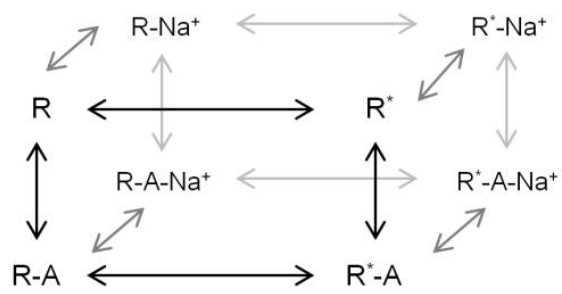

D Mode 2: carrier-off

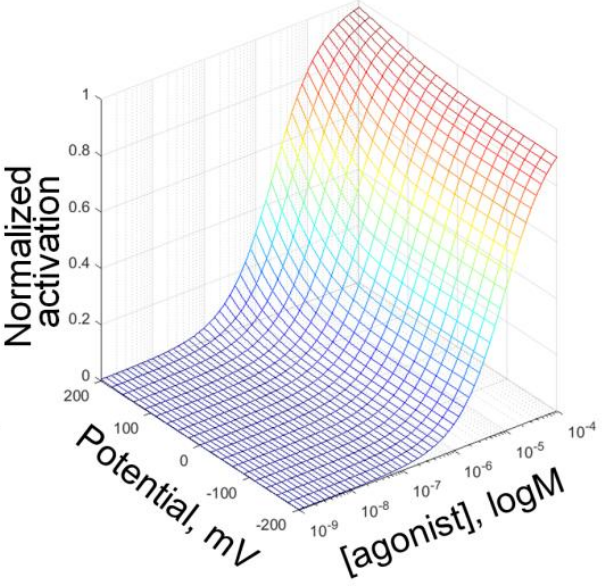

$\mathbf{F}$

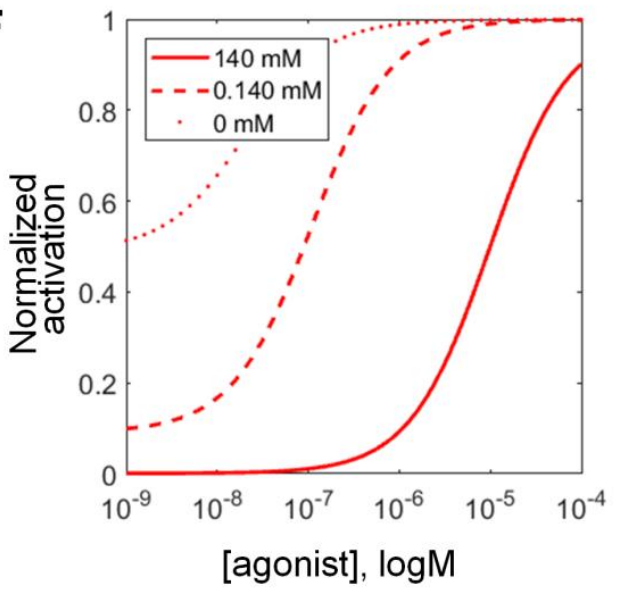

Figure 2. Kinetic models describing the behavior of the $\mathrm{Na}^{+}$ion upon GPCR activation.

188 A. Schematic representation of GPCR activation in carrier-on and carrier-off modes. In both modes, 189 the binding of a $\mathrm{Na}^{+}$ion by a GPCR is much more likely in the inactive state than in the active state.

190 When activation of the receptor is triggered by the agonist binding, $\mathrm{Na}^{+}$leaves its binding site. In mode 1 (carrier-on), $\mathrm{Na}^{+}$escapes to the cytoplasm, thus penetrating the membrane. In mode 2 (carrieroff), $\mathrm{Na}^{+}$escapes back into the extracellular space. B. General scheme of the model that describes the effect of the agonist and $\mathrm{Na}^{+}$as allosteric modulators on the distribution of the receptor between the active $\left(R^{*}\right)$ and inactive $(\mathrm{R})$ states. C, D. Effect of the membrane potential on the concentrationresponse curves of GPCR activation as calculated for the mode 1 (carrier-on) (C) and mode 2 (carrieroff) (D). The curves were plotted with constant allosteric coefficients $(\alpha, \beta, \gamma, \delta)$ from Table $1, M=10^{5}$, $\mathrm{N}=10^{5}$, and $\theta=0.65 ; \mathbf{E}, \mathbf{F}$, Effect of $\left[\mathrm{Na}^{+}\right]_{\text {out }}$ on the concentration-response curves of GPCR activation, membrane voltage was set to $-90 \mathrm{mV}$, other parameters as in Table 1 . 
199 In the absence of a ligand, the fraction of receptors in the $\mathrm{R}^{*}$ state is determined by the equilibrium constant L. Generally, L should be about 1, otherwise the receptor will be blocked in one of the two states. The exact value of L, however, is unknown; its determination requires experimental data on the distribution of active and inactive states in the absence of both $\mathrm{Na}^{+}$ions and ligands, which are difficult to obtain. In this study, we set the value $\mathrm{L}=1$. This value was chosen to produce very little activity at low concentrations of the agonist in the presence of $\mathrm{Na}^{+}$ions, but also to exhibit some activity in their absence, since this would most closely mimic the behavior of experimental systems [26, 27, 30, 32, 33]. Specifically, $\beta_{2}$-adrenergic receptors were biased towards inactive conformation both when studied by ${ }^{19}$ F-NMR and double electron-electron resonance spectroscopy (detergentstabilized samples, $100 \mathrm{mM} \mathrm{NaCl}$ ) [2] and by single-molecule monitoring of fluorescent probes (nanodisc-embedded receptors, $150 \mathrm{mM} \mathrm{NaCl}$ ) [45].

211 The initial values of the agonist and sodium association constants were set to $\mathrm{N}=10^{7} \mathrm{M}^{-1}$ and

$212 \mathrm{M}=10^{3} \mathrm{M}^{-1}$, respectively, in accordance with the physiologically relevant agonist and sodium 213 concentrations, see $[27,49,50]$.

214 The allosteric coefficients $\alpha, \beta, \gamma$, and $\delta$ describe the extent of coupling between the 215 transitions, i.e. their interdependence, see Table 1. The coefficient $\alpha$ reflects the effect of $\mathrm{Na}^{+}$ 216 ion binding on the receptor activation. Based on experimental evidence, $\mathrm{Na}^{+}$ions inhibit 217 receptor activation $[26,28,30-32]$, thus this coefficient should be $<<1$. The coefficient $\beta$ 218 reflects the effect of agonist binding on the activation of the receptor. As agonist binding 219 stimulates receptor activation, this value was expected to be $>1$. The coefficient $\gamma$ reflects 220 the effect of agonist binding on the $\mathrm{Na}^{+}$ion binding. Available crystal structures of GPCR with $\mathrm{Na}^{+}$ion bound usually do not contain an agonist molecule, whereas the structures of the same proteins with agonist bound have no space for a $\mathrm{Na}^{+}$ion [26]; therefore, the value of $\gamma$ was expected to be $<<1$. The triple allosteric interaction coefficient $\delta$ reflects the coupling between all three processes. Probabilities of individual states are also affected by $\mathrm{Na}^{+}$ concentrations, which were set at physiological values of $[\mathrm{Na}]_{\text {out }}=140 \mathrm{mM}$ and $[\mathrm{Na}]_{\text {in }}=10$ mM (Table 1). Further details of the model and its solution are described in Methods. 
Table 1. Initial parameters of the model

229

230

\begin{tabular}{|l|l|l|}
\hline Parameter & Value & Description \\
\hline $\mathrm{M}$ & $10^{3} \mathrm{M}^{-1}$ & Association constant of the sodium ion (initial value) \\
\hline $\mathrm{N}$ & $10^{7} \mathrm{M}^{-1}$ & Association constant of the agonist (initial value) \\
\hline $\mathrm{L}$ & 1 & Receptor activation constant \\
\hline$\alpha$ & $10^{-3}$ & Intrinsic efficacy of sodium: ratio of affinity of sodium for $\mathrm{R}^{*}$ and $\mathrm{R}$ \\
\hline$\gamma$ & $10^{3}$ & Intrinsic efficacy of the agonist: ratio of affinity of the agonist for $\mathrm{R}^{*}$ and $\mathrm{R}$ \\
\hline$\delta$ & $10^{-2}$ & $\begin{array}{l}\text { Binding cooperativity between the sodium ion and the agonist: ratio of } \\
\text { affinity of A for R-Na and R, or of Na for R-A and } \mathrm{R}\end{array}$ \\
\hline $\mathrm{Na}^{+}{ }_{\text {out }}$ & $10^{2}$ & $\begin{array}{l}\text { Activation cooperativity between the sodium ion and the agonist: ratio of } \\
\text { affinity of A for } \mathrm{R}^{*}-\mathrm{Na} \text { and } \mathrm{R}-\mathrm{Na}, \text { or of Na for } \mathrm{R}^{*}-\mathrm{A} \text { and } \mathrm{R}-\mathrm{A}\end{array}$ \\
\hline $\mathrm{Na}^{+}{ }_{\text {in }}$ & $10 \mathrm{mM}$ & {$\left[\mathrm{Na}^{+}\right]$in the extracellular medium } \\
\hline
\end{tabular}

\footnotetext{
${ }^{\mathrm{a}}$ The names of parameters are taken from ref. [42].
}

Fig. S2 shows how the shape of activation curves varies with variation of parameters $\alpha, \beta, \gamma$, and $\delta$ in the carrier-on mode. These concentration - response curves report the sensitivity of the receptor: they show how much agonist is needed to activate the receptor. Fig. S2 shows that increasing the value of $\delta$, which characterizes the coupling between the (i) binding of agonist, (ii) release of the $\mathrm{Na}^{+}$ion into the cytoplasm and (iii) activation of the receptor, increases the sensitivity of the receptor (less agonist is needed for activation, see Fig. S2D).

Based on comparison of the fit curves (Fig. S2) with experimentally measured typical activation curves for several GPCRs, we set the initial values of $\alpha, \beta$, and $\gamma$ to $1000,0.001$, and 0.01 , respectively (Table 1 ). Then the product $\alpha \beta \gamma$ equals 0.01 , which means that the concurrent binding of the $\mathrm{Na}^{+}$ion and agonist shifts the receptor into the inactive state. Such an inactivation could be avoided by setting $\delta$, the triple allosteric interaction coefficient that reflects the coupling between all three processes, at $>>1$. The value of $\delta$ was initially set to 100 , so that the product of multiplication of all coefficients was 1 , see Methods for details.

Because of the charge of the $\mathrm{Na}^{+}$ion, the probabilities of states in Fig. 2B would also be affected by membrane voltage. Since cell cytoplasm is charged negatively relative to the extracellular medium, membrane voltage pushes the $\mathrm{Na}^{+}$ion from the extracellular side to the cytoplasmic side of the membrane. Hence, membrane voltage favors the translocation of the $\mathrm{Na}^{+}$ion (i) from the outside into the $\mathrm{Na}^{+}$-binding site and (ii) from the $\mathrm{Na}^{+}$-binding site into the cytoplasm. In contrast, the retreat of the $\mathrm{Na}^{+}$ion to the extracellular site would be 
hampered by membrane voltage. The energy gap imposed by membrane voltage can be then defined as:

254 where $\Delta \psi$ is the membrane voltage, $e$ is the cation charge, and the coefficient $\theta$ reflects the depth of the $\mathrm{Na}^{+}$-binding site in the membrane, with $\theta=0$ corresponding to the $\mathrm{Na}^{+}$ion on the extracellular side of the membrane and $\theta=1$ corresponding to the $\mathrm{Na}^{+}$ion on the cytoplasmic side of the membrane.

258 Based on the actual position of the $\mathrm{Na}^{+}$ion in available crystal structures (Fig. 1) and assuming a symmetrical distribution of dielectric permittivity value along the transmembrane axis, we have set $\theta=0.65$ for the $\mathrm{Na}^{+}$-binding site in class A GPCRs.

261 Hence, in the inactive conformation, the membrane voltage promotes $\mathrm{Na}^{+}$binding from the extracellular medium by pushing the cation inside the membrane with the force $F_{1}$ (see Eq. 1). In the carrier-on mode, membrane voltage could push the $\mathrm{Na}^{+}$ion from its binding site in the middle of the membrane into the cytoplasm with the force of

266 As shown in Fig. 2C and 2B, the same initial parameters from Table 1 yield different activation curves and different dependence on the membrane voltage depending on the operation mode. In the carrier-on mode, the receptor displays the highest sensitivity at the membrane voltage of $-200 \mathrm{mV}$, while neutral and positive voltage values lead to weaker activation, with more agonist required to reach the same activation level. In the carrier-off mode, the dependence of activation on the membrane voltage is opposite: the receptor is more efficient at positive voltage values; here the difference in activation curves at different voltage values is much less pronounced than in the carrier-on mode.

274 The curves in Fig. 2C, D and Fig. S2 were calculated at fixed physiological concentrations of $275 \mathrm{Na}^{+}$ions in the external medium and in the cytoplasm (Table 1). In Fig. 2, panels E and F 276 show the activation curves as a function of external $\mathrm{Na}^{+}$concentration. Decreasing the $\mathrm{Na}^{+}$ levels increases both the sensitivity of the receptor and the probability of receptor activation in the absence of agonists, in agreement with experimental observations [26, 28, 30-32]. 


\section{Comparison with experimental data}

282 Several studies have reported voltage-dependent signaling in different GPCRs, see Table S1 and $[38,39]$ for reviews. The membrane voltage of physiological sideness (with cytoplasmic side negatively charged) usually activated GPCRs, although in some cases, e.g. in the muscarinic acetylcholine receptor $\mathrm{M}_{1}$, membrane voltage decreased the activity of the receptor [49, 51, 52]. In early studies of voltage-dependent behavior of GPCRs, their activation was followed via downstream reactions, e.g. by measuring the conductance of the GPCR-regulated ion channels [38, 39]. However, the potential voltage-dependence of the channels themselves could make the data interpretation ambiguous. Therefore we limited our scope to the data on voltage dependence of GPCR activation as obtained by using FRETbased biosensors that responded to the outward movement of the transmembrane helix 6 which is directly linked to receptor activation [34, 49, 50]. Using this technique, Rinne and colleagues showed that membrane voltage increased the sensitivity of the $\alpha_{2 \mathrm{~A}}$ adrenoreceptor to norepinephrine [50]. In addition, membrane voltage increased the sensitivity of muscarinic acetylcholine receptors $\mathrm{M}_{3}$ and $\mathrm{M}_{5}$ to their full agonists acetylcholine and carbachol, but decreased the sensitivity to the same full agonists in the case of the muscarinic acetylcholine receptor $\mathrm{M}_{1}$ [49].

We tested whether our model could describe the data of Rinne and colleagues $[49,50]$. To perform the fitting, experimental data points were extracted from respective publications. In each case, fits were separately performed for the carrier-on and carrier-off modes, respectively (Fig. 2). For each mode, two sets of data points (as measured at two voltage values, e.g. -90 and $+60 \mathrm{mV}$ ) were fitted. The two fit curves were calculated with the same parameter sets (see Table 1), with the only difference being the voltage values that were taken from respective experimental data. Both curves were fitted simultaneously by varying only two parameters, namely the $\mathrm{Na}^{+}$binding constant $\mathrm{M}$ and agonist binding constant $\mathrm{N}$, which were kept the same for both voltage values in each case. All other parameters were as in Table 1. In addition, we performed separate fits with $\beta=100$, see Table 2.

308 The fit curves are shown in Fig. 3 and the fit parameters are listed in Table 2. In each case, 309 one of the two tested modes provided a good fit. In cases when the membrane voltage 310 increased the sensitivity of the receptor, the experimental data could be fit by the model in 311 carrier-on mode. For the data in Fig. 3C, where the sensitivity was decreased by membrane 312 voltage, the carrier-off mode provided a good fit. Varying the $\theta$ value, which was initially 313 determined from structure analysis, did not lead to notable fit improvements (data not 
314 shown). It is noteworthy that the agonist association constants in Table 2 correspond to the

315 so-called intrinsic association constants $\left(\mathrm{K}_{\mathrm{a}}\right)$, which could be much smaller than the

316 observable association constants $\left(\mathrm{K}_{\mathrm{obs}}\right)$, see $[44,53]$.

\section{A. $\alpha_{2 A} A R$ with norepinephrine}

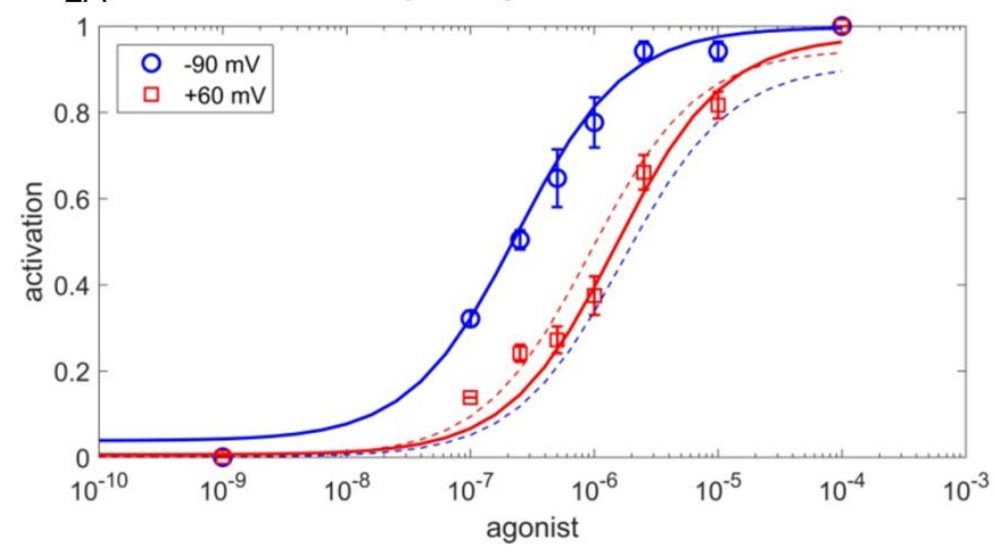

B. $M_{3} R$ with carbachol

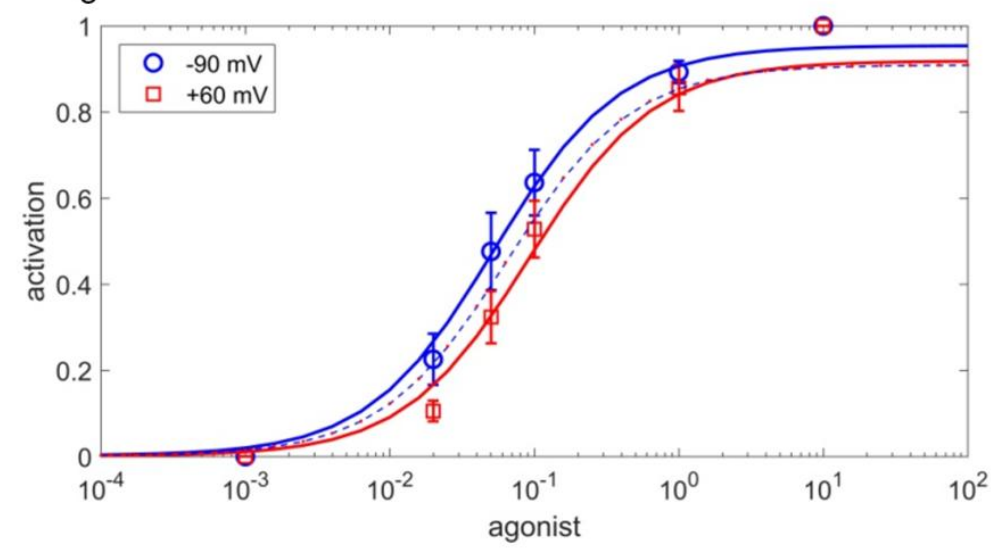

C. $M_{1} R$ with carbachol

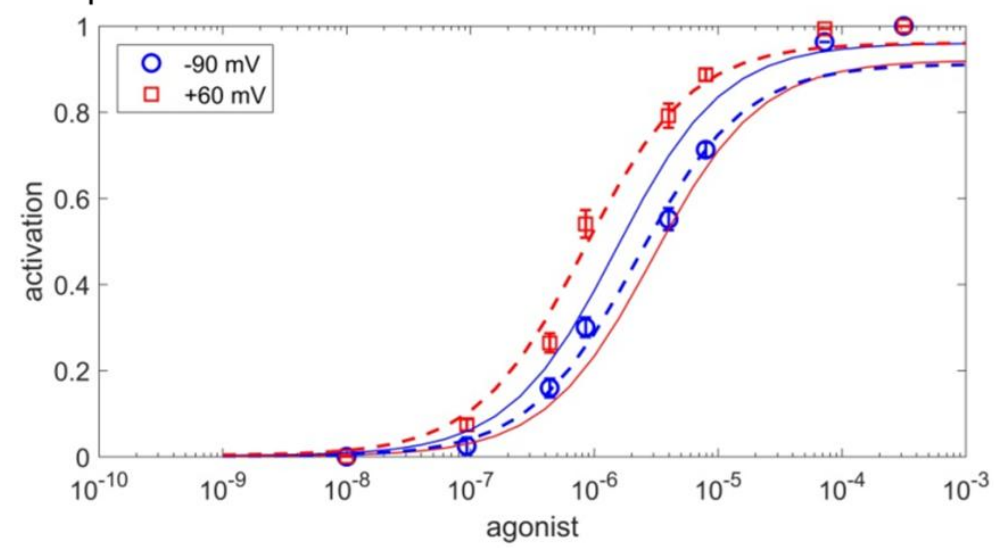

Figure 3. Fitting experimental data of voltage-sensitive GPCR activation.

The fits for the carrier-on mode 1 are shown by solid lines, the fits for the carrier-off mode 2 are shown by dashed lines. A. $\alpha_{2 \mathrm{~A}}$ adrenoreceptor activation by full endogenous agonist norepinephrine, experimental data from [50]. B. Muscarinic $\mathrm{M}_{3}$ receptor activation by full agonist carbachol experimental data from [49]. C. Muscarinic $\mathrm{M}_{1}$ receptor activation by full agonist carbachol, 
Table 2. Sodium ion and agonist binding constants as obtained from fitting experimental data

\begin{tabular}{|c|c|c|c|c|c|}
\hline \multirow[b]{2}{*}{ Receptor - agonist pairing } & \multirow[b]{2}{*}{ Mode } & \multicolumn{2}{|l|}{$\beta=1000$} & \multicolumn{2}{|l|}{$\beta=100$} \\
\hline & & $\begin{array}{l}\mathrm{Na}^{+} \\
\text {association } \\
\text { constant, } \\
\mathrm{M}^{-1}\end{array}$ & $\begin{array}{l}\text { Agonist } \\
\text { association } \\
\text { constant, } \\
\mathbf{M}^{-1}\end{array}$ & $\begin{array}{l}\mathrm{Na}^{+} \\
\text {association } \\
\text { constant, } \\
\mathrm{M}^{-1}\end{array}$ & $\begin{array}{l}\text { Agonist } \\
\text { association } \\
\text { constant, } \\
\mathbf{M}^{-1}\end{array}$ \\
\hline$\alpha_{2 A}-A R$ with norepinephrine & 1 , carrier-on & $2.4 \cdot \times 10^{4}$ & $2.6 \cdot \times 10^{5}$ & $8.7 \cdot x 10^{3}$ & $1.1 \cdot \times 10^{6}$ \\
\hline $\mathrm{M}_{3}$ muscarinic receptor with carbachol & 1 , carrier-on & $3.5 \cdot \times 10^{5}$ & 8.4 & $3.1 \cdot \times 10^{5}$ & 87.9 \\
\hline $\mathrm{M}_{1}$ muscarinic receptor with carbachol & 2, carrier-off & $2.1 \cdot \times 10^{7}$ & $6.4 \cdot \times 10^{5}$ & $2.2 \times 10^{5}$ & $2.6 \cdot \times 10^{6}$ \\
\hline
\end{tabular}

326 By using essentially the same set of parameters from Table 1 and varying only the values $\mathrm{M}$ and $\mathrm{N}$, it was possible to quantitatively fit also the previously obtained experimental data on the influence of membrane voltage on the activation of GPCRs as traced via downstream reactions (Table S1). An example of such a fit is presented in Fig. S3.

330 Our modeling of experimental data speaks against the obligatory coupling between the activation of a GPCR and transmembrane translocation of a $\mathrm{Na}^{+}$ion into the cytoplasm. It appears that in some GPCRs, the $\mathrm{Na}^{+}$ion can retract, upon activation, into the extracellular medium. In most studied cases, however, the experimental data are better described by the carrier-on operation mode where binding of an agonist is mechanistically coupled to the voltage-driven translocation of the $\mathrm{Na}^{+}$ion into the cytoplasm.

\section{Discussion}

\section{Modeling the behavior of GPCRs}

338 Here, staying in the traditional bioenergetics framework, we considered $\mathrm{Na}^{+}$-dependent 339 GPCRs as potential electrogenic $\mathrm{Na}^{+}$carriers. The ability of GPCRs to provide a passage for $340 \mathrm{a} \mathrm{Na}^{+}$ion follows from (i) the results of molecular dynamics simulations [24, 36, 37], (i) the evolutionary relatedness of GPCRs to, and structural similarity with, such dedicated transporters as $\mathrm{Na}^{+}$-dependent bacterial rhodopsin (NR) and channelrhodopsin [7], see the discussion below and Fig. S1, S5; and (iii) the data on voltage-driven charge displacements

344 within GPCRs [52, 54]. Vichery and colleagues argued that the so-called "gating currents" or 345 "sensory currents", measured in response to imposed membrane voltage with some GPCRs $346[52,54]$, may reflect the movement of a $\mathrm{Na}^{+}$ion from its binding site into the cytoplasm [39].

347 To clarify the benefits from $\mathrm{Na}^{+}$translocation, let us consider the thermodynamics of a 348 membrane receptor. An "ultimately sensitive" receptor should stay inactive in the absence of 
agonists and get activated (e.g. by changing its conformation from $\mathrm{R}$ to $\mathrm{R}^{*}$ ) in response to the very first arriving molecule(s) of agonist. In such a system, the free energy needed to drive the conformational change is provided by the binding of agonist; the amount of this free energy is, however, small when the concentration of agonist is comparable with its dissociation constant. Indeed, the free energy of binding can be determined as

$\Delta G=R T \ln \frac{K d}{[L]}$

where $K d$ is the dissociation constant of the ligand (e.g. agonist) and $[L]$ is the concentration of the ligand. Then, if the dissociation constant of an agonist is $10^{-7} \mathrm{M}$, the free energy of its binding will be zero at $10^{-7} \mathrm{M}$ of agonist and only $-6 \mathrm{~kJ} / \mathrm{mol}$ at $10^{-6} \mathrm{M}$ of agonist. With such a small energy input, the activation would be possible only if the equilibrium constant between $\mathrm{R}$ and $\mathrm{R}^{*}$ is small (i.e. close to unity, as in our modeling). Then, however, because the energy of thermal fluctuations is $2.5 \mathrm{~kJ} / \mathrm{mol}$ (one $\mathrm{kT}$ ) at room temperature, $10 \%$ of receptors would stay constantly activated even in the absence of agonist and produce spurious noisy signal.

Selective stabilization of receptors in their inactive state by $\mathrm{Na}^{+}$ions, which are abundant outside the cell, would help to silence the intrinsically noisy GPCRs in the absence of agonist molecules. However, such a noise reduction, at the same time, would decrease the sensitivity of GPCRs. To activate a $\mathrm{Na}^{+}$-blocked receptor, proportionally higher levels of agonists would be needed. This conundrum can be solved only by invoking an external source of free energy and coupling it to the receptor activation. The data on voltage dependence of some GPCRs in Fig. 3A,B and S3 indicate that these GPCRs use the energy of transmembrane electric field to increase their sensitivity. At physiological membrane voltage of about $-100 \mathrm{mV}$, the strength of the electric field that pushes the $\mathrm{Na}^{+}$ion across the membrane is approx. $10^{7} \mathrm{~V} / \mathrm{m}$. The energy of this field could be, however, used only if the receptor activation is mechanistically coupled to the displacement of the ion.

How much free energy could be gained this way in vivo? In experiments where the voltage was varied by $150 \mathrm{mV}$ (between $-90 \mathrm{mV}$ and $60 \mathrm{mV}$, see Fig. 3, S3), only the membrane voltage, but not the $\mathrm{Na}^{+}$concentrations, were varied. In vivo, the movement of the $\mathrm{Na}^{+}$ion would be driven both by the voltage on the cellular membrane $\Delta \psi(\sim-100 \mathrm{mV})$ and concentration difference of $\mathrm{Na}^{+}(140 \mathrm{mM}$ outside versus $<10 \mathrm{mM}$ inside). By analogy with the proton-motive force introduced by Mitchell for describing the proton-motive energy conversion [55], the corresponding sodium-motive force (smf), in the case of $\mathrm{Na}^{+}-$ translocating membrane enzymes, could be defined as 
$s m f=-\Delta \psi+\frac{2.3 R T}{F} \lg \frac{\left[N a^{+}\right]_{o u t}}{\left[N a^{+}\right]_{i n}}=-\Delta \psi+\frac{2.3 R T}{F} \Delta p N a$,

where $2.3 \mathrm{RT} / \mathrm{F}$ is $59.1 \mathrm{mV}$ at $298^{\circ} \mathrm{K}$ [56].

In case of GPCRs, the value of smf would depend on the extent of the coupled transmembrane charge transfer. After the escape of the $\mathrm{Na}^{+}$ion into the cytoplasm, the Asp2.50 residue is unlikely to stay deprotonated and negatively charged in the middle of the membrane, it would rather accept a proton from the external medium [37]. The corresponding displacement of a proton would be driven by membrane voltage; it, however, could be either coupled to the activation of the receptor or not. If proton displacement uncoupled (e.g. because protonation of Asp2.50 is slow and happens after the activation of the GPCR), the amount of free energy derived from the $\mathrm{Na}^{+}$translocation could be estimated as $(\sim-\Delta \psi(1-$ $\left.\theta)+\frac{2.3 R T}{F} \Delta p N a\right)$ or $\sim 120 \mathrm{meV}$. As it follows from Fig. $2 \mathrm{C}$, the $s m f$ of $120 \mathrm{meV}$, at $\delta>>1.0$, would increase the receptor sensitivity up to an order of magnitude. If the reprotonation of Asp2.50 is coupled to the activation, as argued by Vickery and colleagues [37], the respective smf of $\sim 170 \mathrm{mV}\left(\sim-\Delta \psi+\frac{2.3 R T}{F} \Delta p N a\right)$ could increase the sensitivity by almost two orders of magnitude (see Fig. 2C). Furthermore, reprotonation of Asp2.50 could be productive in some GPCRs and futile in other GPCRs contributing to the variations of voltage effects, as reviewed in [37, 39].

399 Our modeling of experimental data (Fig. 3 and S3) supports the idea that $\mathrm{Na}^{+}$-translocating 400 GPCRs, when operating in the carrier-on mode, could use the energy of the transmembrane electric field to amplify the signal. Devices that use the energy of external electric field to amplify a weak signal are called field effect transistors.

403 Additionally, the same electric field, by preventing the escape of the bound $\mathrm{Na}^{+}$ion to the extracellular side and stabilizing the inactive conformation, would decrease the noise in the absence of agonist. Hence, $\mathrm{Na}^{+}$-dependent GPCRs can work as electrochemical field effect transistors in which the electric field is additionally used to suppress the noise.

407 There are even more benefits from coupling translocation of the $\mathrm{Na}^{+}$ion with receptor activation. Since the equilibrium constant between the active and inactive states of GPCRs is low (Table 1), the equilibrium, in principle, could be shifted towards the active state in multiple ways in response to binding of various ligands to different patches in the ligandbinding pocket. The above-described amplification mechanism, however, would be involved 
412 only when the binding of an agonist molecule would prevent the retreat of the $\mathrm{Na}^{+}$ion into 413 the extracellular media upon activation [26]. The $\mathrm{Na}^{+}$binding site is connected with the 414 extracellular space by a polar cavity (Fig. 1A, B), so that the retreat of a $\mathrm{Na}^{+}$ion through this 415 cavity upon activation is mechanistically easier than its corkscrewing in the opposite 416 direction through the layer of hydrophobic residues - unless the agonist binds in such a 417 specific way that the retreat of the $\mathrm{Na}^{+}$ion is blocked and it is forced to escape in the opposite 418 direction. Apparently, only some specific modes of agonist binding would prevent the retreat 419 of the $\mathrm{Na}^{+}$ion and thus enable the coupling between its electrogenic translocation into the 420 cell and the receptor activation. The signal of such agonist molecules would be amplified by 421 electric field (carrier-on mode), whereas the signal of other, e.g. partial agonists would be 422 weakened by the field (carrier-off mode), which would dramatically increase the chemical 423 selectivity of the receptor.

424 It could be anticipated that the endogenous agonists of studied GPCRs should be among those 425 effectors whose signals are amplified by membrane voltage. Indeed, in the muscarinic 426 acetylcholine receptor $\mathrm{M}_{2}$, the membrane voltage potentiated the signal from the endogenous 427 full agonist acetylcholine, but decreased the signal from the drug pilocarpine, a partial 428 agonist, see Table S1, Fig. S3 and [57, 58]. Additionally, the voltage sensitivity of the $\mathrm{M}_{2}$ 429 receptor was shown to be altered by mutations in the orthosteric ligand-binding site, 430 indicating a direct connection between the agonist binding and voltage effects [57].

431 In the case of the muscarinic acetylcholine receptor $\mathrm{M}_{3}$, the membrane voltage increased the 432 sensitivity to full agonists acetylcholine (endogenous) and carbachol (artificial), but 433 decreased the sensitivity to choline or pilocarpine, see Table S1, Fig. 3B and [49]. In support 434 of their suggestion that voltage-sensitivity is defined by the specific binding mode of each signaling molecule to the receptor, Rinne and coworkers have shown that the replacement of 436 Asn6.52 in the $\mathrm{M}_{3}$ receptor by Gln reversed the voltage effect in case of the artificial agonist 437 carbachol but did not affect the behavior of the endogenous agonist acetylcholine [49]. The 438 authors concluded that their data buttress the importance of the $6^{\text {th }}$ helix for the mechanics of acetylcholine receptors.

440 Similarly, membrane voltage increased the sensitivity of dopamine $\mathrm{D}_{2 \mathrm{~S}}$ receptor to its native 441 agonist dopamine, but decreased the sensitivity to $\beta$-phenethylamine, $p$ - and $m$-tyramine, see 442 Table S1 and [59-61]. 
443 By contrast, activation of the muscarinic acetylcholine receptor $M_{1}$ both by endogenous 444 agonist acetylcholine and artificial agonist carbachol was depressed by membrane voltage, 445 see Fig. 3C and Table S1. This behavior could be better described by the carrier-off mode, 446 where the $\mathrm{Na}^{+}$ion retreats into the extracellular medium upon activation. It appears that the $447 \mathrm{M}_{1}$ receptor does not translocate $\mathrm{Na}^{+}$even in the presence of its endogenous agonist, which 448 may have sense if the activity of this receptor is suppressed by membrane voltage.

449 Finally, Table S1 also reports several cases where receptors were insensitive to membrane 450 voltage. Mechanistically, this could happen if the displacement of the $\mathrm{Na}^{+}$ion - in either direction - is uncoupled from the activation $(\delta<<1.0)$. For instance, $\mathrm{Na}^{+}$ion could retreat before the major conformational change/activation occurs.

453 In summary, the suggested model allowed us to qualitatively describe the data on voltage 454 dependence of several $\mathrm{Na}^{+}$-dependent GPCRs by using the same set of fixed parameters for receptor activation and by varying only the affinities to the agonist and the $\mathrm{Na}^{+}$ion. It appears that the translocation of a $\mathrm{Na}^{+}$ion across the membrane and into the cytoplasm concomitantly with the receptor activation increases both the sensitivity and selectivity of GPCRs.

\section{Structural elements of the coupling mechanism}

460 Here we argue that the $\mathrm{Na}^{+}$ion serves as the physical moiety that couples the GPCR with the external electrochemical gradient by pushing, as a cannon ball, through the layer of hydrophobic residues and promoting the conformational change in the receptor. To identify the structural aspects of the coupling mechanism, we superposed crystal structures of the muscarinic acetylcholine receptor $\mathrm{M}_{2}$ in its inactive state (PDB entry $3 \mathrm{UON}$ [14]) and in the active state (PDB: 4MQT [13]), see Fig. 1C. This pair of structures was chosen because of the clear-cut differences between the inactive and active structures [13,62] and the reported voltage dependence of muscarinic receptors, see Table S1, Fig. S3 and [51, 52, 63]. The results of our analysis, however, should also be applicable to other Class A GPCRs because of the high sequence identity of the regions surrounding the sodium ion among the members of this class [26]. They share, for example, motifs LxxxD in helix 2, DRY in helix 3, WxP in helix 6, and NPxxY in helix 7, see Fig. 1C,D and [64-66]. Fig. 1D shows the positions of these motifs, whereas Table 3 reports the extent of their conservation. 
Table 3. Conservation of functionally important residues in Class A GPCRs.

\begin{tabular}{|c|c|c|c|c|c|c|}
\hline \multirow{2}{*}{$\begin{array}{l}\text { Residue in } \mathrm{M}_{2} \text { muscarinic } \\
\text { acetylcholine receptor } \\
\text { (PDB: } 3 \mathrm{UON} \text { ) }\end{array}$} & \multirow{2}{*}{$\begin{array}{l}\text { Generic } \\
\text { number }\end{array}$} & \multicolumn{2}{|c|}{ Most common residue } & \multicolumn{2}{|c|}{$\begin{array}{lll}\text { Second most } & \text { common } \\
\text { residue } & & \\
\end{array}$} & \multirow[t]{2}{*}{ Residue type, $\%$} \\
\hline & & $\mathrm{AA}$ & $\%$ & AA & $\%$ & \\
\hline & \multicolumn{6}{|c|}{$\mathrm{Na}^{+}$coordination } \\
\hline Asn41 & 1.50 & $\mathrm{~N}$ & 98 & $S$ & 1 & Polar, 100 \\
\hline Asp69 & 2.50 & $\mathrm{D}$ & 92 & $\mathrm{~N}$ & 3 & Polar, 98 \\
\hline Ser110 & 3.39 & $\mathrm{~S}$ & 72 & $\mathrm{~T}$ & 8 & Polar, 83 \\
\hline Trp400 & 6.48 & $\mathrm{~W}$ & 68 & $\mathrm{~F}$ & 16 & Aromatic, 87 \\
\hline Asn432 & 7.45 & $\mathrm{~N}$ & 67 & $S$ & 11 & Polar, 93 \\
\hline \multirow[t]{2}{*}{ Ser433 } & 7.46 & $\mathrm{~S}$ & 64 & $\mathrm{C}$ & 13 & Polar, 72 \\
\hline & \multicolumn{6}{|c|}{ WxP motif } \\
\hline Thr399 & 6.47 & $\mathrm{C}$ & 71 & $\mathrm{~S}$ & 10 & Small, 86 \\
\hline Trp400 & 6.48 & $\mathrm{~W}$ & 68 & $\mathrm{~F}$ & 16 & Aromatic, 87 \\
\hline \multirow[t]{2}{*}{ Pro402 } & 6.50 & $\mathrm{P}$ & 99 & N/A & N/A & Helix kink, 99 \\
\hline & \multicolumn{6}{|c|}{ Hydrophobic shell around the $\mathrm{Na}^{+}$pocket } \\
\hline Leu65 & 2.46 & $\mathrm{~L}$ & 90 & M & 4 & Hydrophobic, 99 \\
\hline Val111 & 3.40 & I & 40 & $\mathrm{~V}$ & 24 & Hydrophobic, 88 \\
\hline Leu114 & 3.43 & $\mathrm{~L}$ & 73 & I & 10 & Hydrophobic, 98 \\
\hline Ile117 & 3.46 & I & 56 & $\mathrm{~L}$ & 16 & Hydrophobic, 99 \\
\hline Ile392 & 6.40 & $\mathrm{~V}$ & 37 & I & 28 & Hydrophobic, 93 \\
\hline Leu393 & 6.41 & $\mathrm{~V}$ & 41 & $\mathrm{~L}$ & 20 & Hydrophobic, 91 \\
\hline \multirow[t]{2}{*}{ Phe396 } & 6.44 & $\mathrm{~F}$ & 75 & $\mathrm{~V}$ & 4 & Hydrophobic, 92 \\
\hline & \multicolumn{6}{|c|}{ Second hydrophobic shell } \\
\hline Val44 & 1.53 & $\mathrm{~V}$ & 65 & A & 14 & Hydrophobic, 92 \\
\hline Ile62 & 2.43 & $\mathrm{~L}$ & 36 & $\mathrm{I}$ & 35 & Hydrophobic, 97 \\
\hline Trp148 & 4.50 & $\mathrm{~W}$ & 96 & $\mathrm{~F}$ & 1 & Hydrophobic, 99 \\
\hline Pro198 & 5.50 & $\mathrm{P}$ & 79 & $\mathrm{~V}$ & 5 & Hydrophobic, 95 \\
\hline Met202 & 5.54 & I & 33 & $\mathrm{M}$ & 30 & Hydrophobic, 90 \\
\hline Tyr206 & 5.58 & $\mathrm{Y}$ & 72 & $\mathrm{~S}$ & 5 & Hydrophobic, 86 \\
\hline \multirow[t]{2}{*}{ Ile389 } & 6.37 & $\mathrm{~L}$ & 38 & V & 21 & Hydrophobic, 91 \\
\hline & \multicolumn{6}{|c|}{ NPxxY motif } \\
\hline Asn436 & 7.49 & $\mathrm{~N}$ & 72 & $\mathrm{D}$ & 20 & Polar, 98 \\
\hline Pro437 & 7.50 & $\mathrm{P}$ & 94 & $\mathrm{~A}$ & 2 & Hydrophobic, 98 \\
\hline \multirow[t]{2}{*}{ Tyr440 } & 7.53 & $\mathrm{Y}$ & 89 & $\mathrm{~F}$ & 4 & Aromatic,93 \\
\hline & \multicolumn{6}{|c|}{ DRY motif (ionic lock) } \\
\hline Asp120 & 3.49 & $\mathrm{D}$ & 64 & $\mathrm{E}$ & 21 & Polar, 97 \\
\hline $\operatorname{Arg} 121$ & 3.50 & $\mathrm{R}$ & 95 & $\mathrm{H}$ & 1 & Polar, 98 \\
\hline Tyr122 & 3.51 & $\mathrm{Y}$ & 66 & $\mathrm{~F}$ & 10 & Aromatic, 87 \\
\hline
\end{tabular}

Residue conservation is calculated from the alignment of human Class A (Rhodopsin-like) GPCRs in the

476 GPCRdb database [67] (not including olfactory receptors). Locations of the functionally relevant residues in the 477 protein structure are shown in Fig. 1. 
478 The crystal structures of the muscarinic acetylcholine receptor $\mathrm{M}_{2}$ in the active and inactive 479 state (Fig. 1A-C) differ in the conformation of helix 6 and, specifically, positions of Trp400 480 (6.48), Leu65 (2.46) and the residues of the NPxxY motif (Fig. 1C, residue numbers for the 481 PDB entry 4MQT). In the inactive state of the $\mathrm{M}_{2}$ receptor, a large cavity above the sodium 482 site connects it with the extracellular space, while the cytoplasmic cavity protracts only up to 483 the residues of the NPxxY motif. As discussed earlier [24, 36, 37, 68, 69], the connection 484 between the two cavities is blocked by a layer of hydrophobic residues. In Fig. 1, this 485 hydrophobic layer contains Leu65 (2.46), Leu114 (3.43), Val111(3.40), Ile117(3.46), 486 Ile392(6.40), Leu393(6.41) and Phe396(6.44) (Fig. 1C,D). These hydrophobic residues in 487 helices 2, 3 and 6 were previously implicated in controlling the activation-related 488 conformational changes [24, 36, 37, 68, 69]. Most of these residues are conserved in class A 489 GPCRs (Table 3). The above-listed residues of the hydrophobic barrier are supported 490 structurally by a second shell of conserved hydrophobic residues: Val44(1.53), Ile62(2.43), 491 Trp148(4.50), Pro198(5.50), Met202(5.54), Tyr206(5.58), and Ile389(6.37). These residues appear to be functionally important: their positions are almost always taken by hydrophobic residues in the class A GPCRs, and in many cases not just the hydrophobic nature, but even the specific residue types are highly conserved (see Table 3 ).

In Fig. 1, the hydrophobic layer is centered on Leu65 (Leu2.46) of the conserved LxxxD motif. Leucines in a helix generally prefer one of two rotamers [70], and a rotamer search for Leu2.46 reveals two clearly preferred rotamers at this position (Fig. S4A). After reinterpretation of the X-ray data of the PDB entry 3UON by the PDB_REDO team [71], Leu2.46 adopts the conformation shown in Fig. 4A and S4B, which corresponds to the lower of the two preferred rotamers in Fig.S4A. The upper of the two rotamer positions is not available to Leu2.46 in the $3 \mathrm{UON}$ structure because the Leu side chain would clash with Asp2.50 and Tyr7.53. Notably, in the active structure of the same receptor (PDB: 4MQT), Leu2.46 is observed in the upper rotamer, see Fig. 1C, S4C. If Leu2.46 is placed in the upper rotamer in the structure of the inactive receptor as envisioned in Fig. 4B and S4D, the two cavities get connected, indicating that water and small ions could freely traverse the GPCR helix bundle. Hence, formation of a passage for a $\mathrm{Na}^{+}$ion requires releasing the steric hindrances by Asp2.50 and Tyr7.53, which prevent rotation of Leu2.46 into the upper rotamer position. 
510

511

512

513

514

515

516

517

518

519

520

521

522

523

524

525

526

527

528

529

530

531

532

533

534
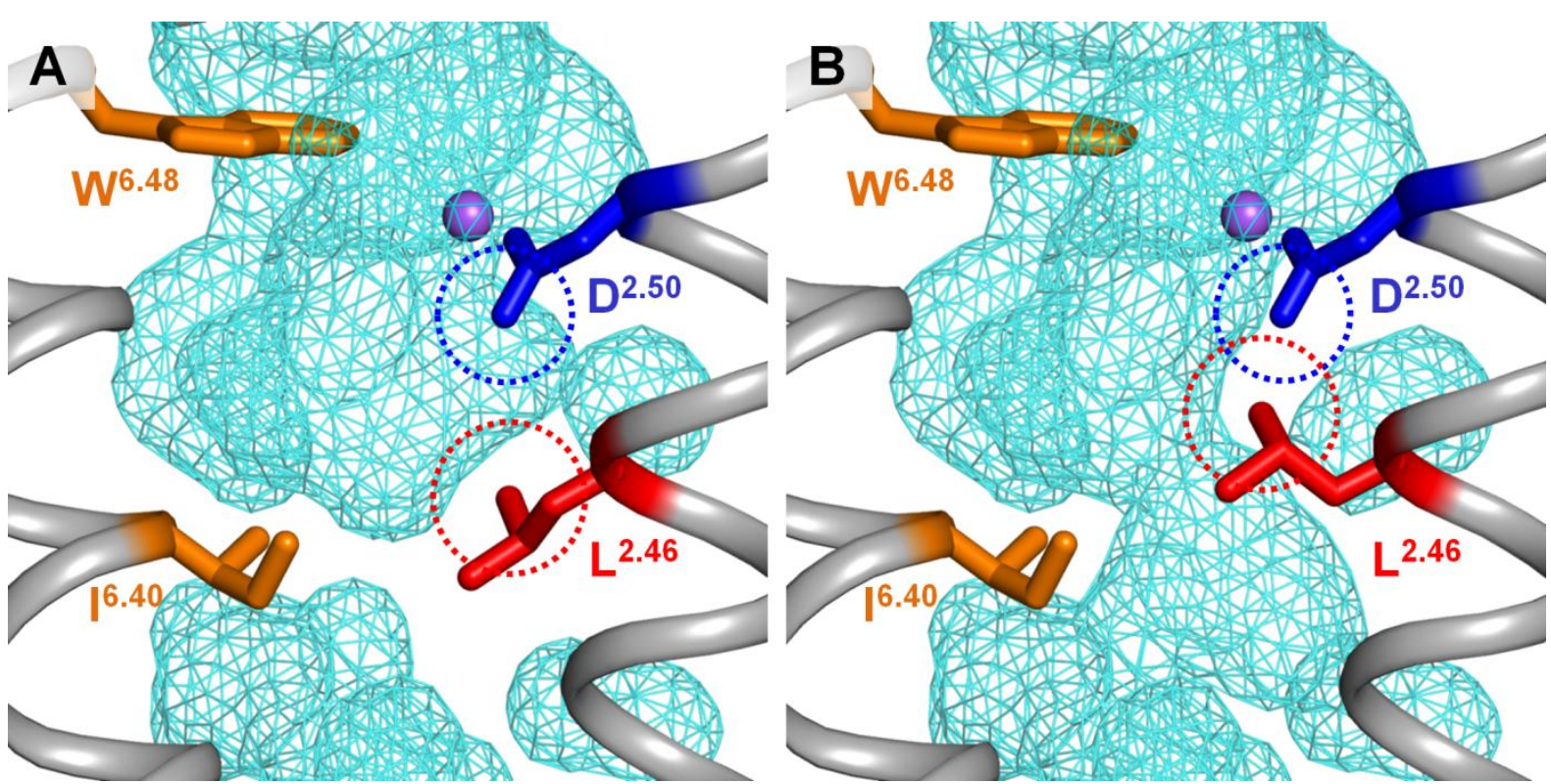

Figure 4. Suggested pathways of Na escape to the cytoplasm upon GPCR activation in the muscarinic acetylcholine receptor $\mathbf{M}_{2}$.

The protein is shown in gray, $\mathrm{Na}^{+}$ion is in purple, solvent-accessible surface with solvent radius 1.12 $\AA$ (corresponding to the $\mathrm{Na}^{+}$ion) is shown as blue mesh. A. Sodium-binding cavity in the $\mathrm{M}_{2}$ receptor in the antagonist-bound inactive state (PDB 3UON). B. A minor rotameric transition of Leu2.46 alone is enough to open the connection between two inner cavities, allowing the $\mathrm{Na}^{+}$ion passage through the layer of conserved hydrophobic residues (see also Fig. S4). The dashed circles mark the Van der Waals radii as calculated by the PyMol v 1.7 software [72].

A minor rotameric transition of the strictly conserved Leu2.46 can open a conduit for voltage-driven translocation of $\mathrm{Na}^{+}$ion into the cell (Fig. 4, S4). Leu2.46 and Asp2.50 form the highly conserved motif LxxxD in helix 2, (Table 3, Fig. 6) where Asp2.50, owing to its negative charge, is the strongest ligand of the $\mathrm{Na}^{+}$ion. While Asp2.50 serves as a $\mathrm{Na}^{+}$ligand, Leu2.46 controls the interface between helices 2 and 3. In the NR, the transmembrane ion passage is formed by helices 3,6 and 7 [7, 73, 74] and is likely to be contributed by same helices in GPCRs [7, 24, 26]. Based on the structure analysis (Fig. 4, S4), we suggest that the rotameric change of Leu2.46 upon GPCR activation plays a key role in coupling the voltagedriven $\mathrm{Na}^{+}$translocation into the cell with the activation of GPCRs.

Numerous alanine screening experiments, performed on different GPCRs, showed an altered function in Leu2.46 mutants, see e.g. [75]. The results of such experiments, however, are difficult to interpret. If Leu2.46 is indeed, as we suspect, involved in the coupling of GPCR activation with $\mathrm{Na}^{+}$translocation, then its replacement would affect both these processes with an unpredictable outcome for the function. More informative is the observation, obtained upon alanine scanning of the human adenosine $\mathrm{A}_{2 \mathrm{~A}}$ receptor, that the mutation of Leu2.46 to 
535 Ala (L48A) dramatically increased the thermostability of the receptor [76]. The temperature

$536 \mathrm{Tm}$ at which $50 \%$ of the solubilized receptor could bind ligand after 30 min thermo537 incubation increased from $28.5^{\circ} \mathrm{C}$ in the wild-type protein to $42.5^{\circ} \mathrm{C}$ in the Leu2.46Ala 538 mutant. The two second-best mutations increased $\mathrm{Tm}$ only to $34.5^{\circ} \mathrm{C}$. The L48A mutation 539 apparently fixed the human adenosine $\mathrm{A}_{2 \mathrm{~A}}$ receptor in a (thermo)stable, active conformation 540 [76].

541 Poor stability is a common property of GPCRs, which hindered their crystallization for 542 several decades. This instability is an intrinsic property; the sensitivity of GPCRs is 543 determined by their ability to switch between two different conformations with similar 544 energies. Dramatic stabilization of the active conformation of $\mathrm{A}_{2 \mathrm{~A}}$ receptor after replacing 545 Leu2.46 by the smaller Ala indicates that the conformation of the bulky hydrophobic side 546 chain of Leu2.46 is indeed keeping the balance between the active and inactive 547 conformations by serving as an important "weak spot" [77]. At the same time, Leu2.46 548 appears to control the $\mathrm{Na}^{+}$path (see Fig. 4, S4), which points to this strictly conserved residue 549 as the key coupling moiety in GPCRs.

550 The coupling between the electrogenic $\mathrm{Na}^{+}$translocation and GPCR activation would be achieved if the agonist binding decreases the affinity of GPCR for the $\mathrm{Na}^{+}$ion. Indeed, keeping the $\mathrm{Na}^{+}$ion in the middle of the hydrophobic membrane is energetically very demanding because of the high desolvation penalty for a positively charged small cation [78]. In the well-studied $\mathrm{Na}^{+}$-dependent ATP synthases, binding of the $\mathrm{Na}^{+}$ion in the middle of the membrane requires six ligands [79, 80]; a loss of even one of them transforms a $\mathrm{Na}^{+}-$ translocating enzyme into a proton-translocating one [79, 81]. The detachment of $\mathrm{Na}^{+}$from its binding site could be mediated by Trp6.48. This residue is strictly conserved in most class A GPCRs (Table 3) and changes its conformation in response to agonist binding, see Fig. 1C and $[2,9,19-25]$. Specifically, in the structure of the $\delta$-opioid receptor (PDB: 4N6H)

560 Trp274(6.48) interacts with the $\mathrm{Na}^{+}$ion via a water molecule [7, 15]; same interaction can be seen in structures of $A_{2 A}$ adenosine receptor (PDB 4EIY) and $\beta_{1}$-adrenoceptor (PDB 5A8E). In all likelihood, Trp6.48 participates in a hydrogen-bonded network also in other class A

563 GPCRs. If the system of bonds around the $\mathrm{Na}^{+}$ion gets destabilized in response to the ligand binding, the further stay of the $\mathrm{Na}^{+}$ion in the middle of the membrane would not be possible. If the retreat path is blocked by the bound agonist, the $\mathrm{Na}^{+}$ion would swing in the pocket until, being pushed by electric field, it enforces the twist of Leu2.46 residue into the upper rotamer. This rotameric transition demands, however, to resolve the steric clash with Asp2.50 
that is located just one helix turn away (Fig. 4B). Asp2.50 is engaged in binding of $\mathrm{Na}^{+}$ion and would not get aside as long as the $\mathrm{Na}^{+}$ion stays bound. Hence, the breakage of the bond between the $\mathrm{Na}^{+}$ion and Asp2.50 is a precondition of the isomeric transition of Lys2.46 and opening of the cytoplasmic $\mathrm{Na}^{+}$conduit (carrier-on operation mode, Fig. 2C, 3A, B). Alternatively, the $\mathrm{Na}^{+}$ion could retreat, against the electric field, into the extracellular space. In this case, the electric field would prevent, rather than promote, the GPCR activation (carrier-off mode, Fig. 2D, 3C). After the escape of the $\mathrm{Na}^{+}$ion, Tyr7.53 makes a new hydrogen bond, via a water bridge (with Tyr5.58 in mammals), whereas the Asn7.49 residue of the NPxxY motif turns towards Asp2.50 and forms a new, alternative hydrogen bond network, which is seen in the "active" crystal structures (Fig. 1B, 1C) [22-24]. These new hydrogen bonds prevent the return of the $\mathrm{Na}^{+}$ion and stabilize the active conformation of the receptor, which is accompanied by displacement of several TM helices and closing of the $\mathrm{Na}^{+}$-binding pocket and of the cytoplasmic $\mathrm{Na}^{+}$path (Fig. 1B, S4C). As a result, the escape of the $\mathrm{Na}^{+}$ion gets thermodynamically coupled with the GPRC activation.

Our structural inspection of cavities in GPCRs showed that the $\mathrm{Na}^{+}$ion might escape from the helical bundle of GPCR either after reaching the water phase from the cytoplasmic side (dashed line in Fig. 5A) or, even earlier, by slipping between helices 2 and 3 at the level of the DRY motif (dashed line Fig. 5B). In the latter case, the $\mathrm{Na}^{+}$ion would be released into the layer of phosphate groups of phospholipids. Their negative charges, serving as potent alternative $\mathrm{Na}^{+}$ligands, could attract the $\mathrm{Na}^{+}$ion and help it to slide between the helices. For the $\mathrm{Na}^{+}$ion, in fact, there is no need to get any further. Molecular dynamics simulations of phospholipid membranes showed that $\mathrm{Na}^{+}$ions reside among the phosphate groups and compensate their negative charges [82].

We have observed a continuous path for the $\mathrm{Na}^{+}$ion only when the GPCR is in the inactive conformation and Leu2.46 is in the upper rotamer typical for the active conformation (Fig. $4 \mathrm{~B}, \mathrm{~S} 4 \mathrm{D})$, which explains why the path is not seen either in the active or in inactive structures (Fig. 1, 4A, S4B, C). Owing to the constriction by the second shell of hydrophobic resides (Table 3, Fig. 1D), the probability of a spontaneous opening of the path should be low, which might explain the relatively high activation energy of the conformational change in GPCRs [20, 47, 48]. Otherwise, $\mathrm{Na}^{+}$ions would constantly leak through GPCRs. While the importance of Asp2.50, Trp6.48 and Tyr7.53 for activation of GPCRs and formation of a $\mathrm{Na}^{+}$-translocating passage has been widely discussed, see e.g. [2, 22-24, 36, 37], the control function of Leu2.46, to our knowledge, has not been specifically addressed until now. 
601
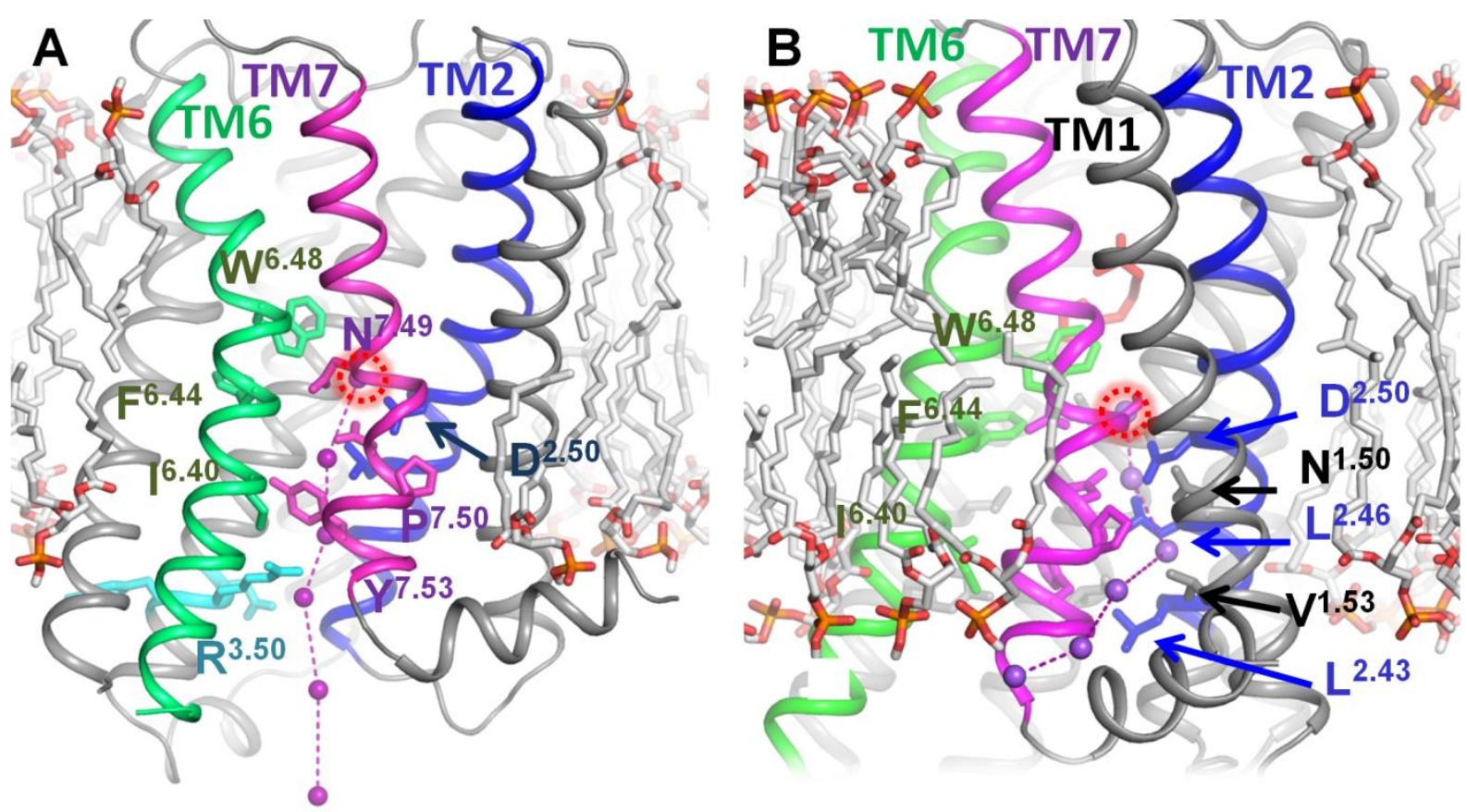

602

603

604

605

606

607

608

609

610

611

612

613

614

615

616

617

618

619

620

621

622

623

624

625

626

Figure 5. Suggested pathways of $\mathrm{Na}^{+}$escape to the cytoplasm upon GPCR activation, based on the structure of the $\mathrm{M}_{2}$ receptor (PDB: 4MQT).

A. Putative exit pathway for the $\mathrm{Na}^{+}$ion via the center of the heptahelical bundle. B. An alternative exit pathway via the pocket between helices 1,2, and 7 . Hypothetical intermediate positions of the $\mathrm{Na}^{+}$ion are shown as purple spheres; the initial position, inferred from the position of $\mathrm{Na}^{+}$in the structures of inactive GPCRs, is indicated by the red dashed circle. Helices 2, 6, and 7 are colored blue, green and purple, respectively; conserved residues listed in Table 3 are shown as sticks. The ionic lock residues are shown in cyan. CHARMM-GUI software [83] was applied to construct the lipid molecules of the membrane surrounding the receptors (shown as grey sticks).

\section{Evolutionary considerations:}

Earlier, the structure superposition of the $\mathrm{Na}^{+}$-translocating rhodopsin from Dokdonia eikasta (NR), and Na-bound GPCRs allowed us to produce a structure-guided alignment of MRs and GPCRs and to suggest the emergence of GPCRs from $\mathrm{Na}^{+}$translocating MRs [7]. Here we have updated this alignment by including the natural (not chimeric) channelrhodopsin 2, the structure of which was recently resolved [84] (ChR2, Fig. S5). As seen in Fig. S5, the $\mathrm{Na}^{+}-$ coordinating residues of GPCRs correspond to the ion-coordinating residues from both NR and ChR2. The pivot Trp6.48 residue of the conserved WxP motif remains the only conserved residue between GPCRs and MRs, in agreement with the movement of the cytoplasmic half of helix 6 as the major conformational change both in MRs [85-87] and GPCRs $[2,9,10,20]$. In addition to the previously reported similarities with NR, the updated alignment shows that Asp2.50 of GPCRs corresponds to a glutamate residue in helix 2 of ChR2, whereas the strictly conserved Trp4.50 of GPCRs is matched by a Trp residue in 
627 ChR2 (Fig. S5). The conservation patterns for functionally important residues between NR and GPCRs, on one hand, and ChR2 and GPCRs, on the other hand, overlap only partially (Fig. S5). It appears that the $\mathrm{Na}^{+}$-translocating, MR-type ancestors of GPCRs could have combined features of NR and ChR2.

631 As discussed previously [7], the original $\mathrm{Na}^{+}$-translocating MR could have evolved into an 632 ancestral GPCR after losing its retinal moiety. A bound $\mathrm{Na}^{+}$ion could stabilize the helical 633 bundle after the loss of the retinal. Formation of a permanent binding site for the $\mathrm{Na}^{+}$ion 634 within an MR is quite feasible. Balashov and colleagues, by substituting Glu for Asp251 in the NR of Gillisia limnaea (which approx. corresponds to the $\mathrm{Na}^{+}$ligand Asn7.45 of GPCRs, see Fig. 1, 4, S4 and Table 3), were able to create a high-affinity binding site for the $\mathrm{Na}^{+}$ion in the middle of the membrane [88].

638 The structural similarity between GPCRs and ChR2 implies possible similarities in their 639 mechanisms. It was shown that photoactivation of ChR was coupled not only with the motion 640 of helix 6 , but also with a rotation of helix 2 [87]. Hence, the functional mobility of helix 2 , 641 which carries the LxxxD motif, may also have been inherited from MRs.

642 The elements of above-described coupling machinery, including an Asp residue in the middle 643 of the helix 2, could be seen already in representative GPCR-like proteins of early-branching 644 eukaryotes, such as Protozoa, primitive Metazoa and plants, which are aligned in Fig. 6. 645 Here, an Asp residue in the position that corresponds to Asp2.50 of class A GPCRs can be 646 considered an indication of the presence of a $\mathrm{Na}^{+}$-binding site. Otherwise, maintaining an 647 Asp residue in the middle of the membrane would be energetically costly and this Asp would 648 be prone to be lost in the course of evolution, as discussed below. As follows from Fig. 6, 649 early-branching GPCR-like proteins with a counterpart of Asp2.50 often have potential $\mathrm{Na}^{+}$ 650 ligands also in the positions of other $\mathrm{Na}^{+}$ligands of class A GPCRs.

651 The suggested key role of Leu2.46 in controlling GPCR activation is supported not only by 652 its already mentioned high degree of conservation within class A GPCRs (90\%, see [36, 64] 653 and Table 3), but also by its conservation within all GPCR-like proteins, even those lacking 654 Asp2.50 (Fig. 6), which is unusual for a hydrophobic residue and indicates that the shape of 655 the side chain of Leu2.46 is particularly important. Trp6.48, the only residue that is conserved 656 between MRs and GPCRs (Fig. S5), is highly but not universally conserved within GPCRs: it 657 is replaced by Tyr in some Alveolata and by Phe in the protease-activated receptor 1 (PAR1) of Metazoa. In addition to Leu2.46, hydrophobic/aromatic residues are well conserved in the 
659 positions $3.40,3.46,6.40$ and 6.44 , which correspond to the hydrophobic core of class A 660 GPCRs, see Table 3 and $c f$. Fig. 1D and 6. Residues Asn7.49 and Tyr7.53 from the NPxxY 661 motif are all highly conserved. Finally, the characteristic motif DRY of the TM3 is absent in 662 plants and most protozoa.

663 Hence, sequence comparisons of animal class A GPCRs with evolutionarily oldest, $\mathrm{Na}^{+}-$ 664 binding, GPCR-like proteins (Fig. 6) support our suggestion on the importance of Leu2.46, 665 Asp2.50, Trp6.48, Asn7.49, Tyr/Phe7.53 and the set of tightly packed, conserved 666 hydrophobic residues for the function of $\mathrm{Na}^{+}$-binding GPCRs and, specifically, for the 667 coupling between their activation and $\mathrm{Na}^{+}$translocation. In contrast, the DRY motif is absent 668 from the sequences of GPCRs from plants and Alveolata and appears to be a somewhat later 669 acquisition.

670 Our inspection showed that eukaryotic genomes contain numerous GPCR-like sequences, 671 both with and without counterparts of Asp2.50. The latter sequences (some are shown in Fig. 672 6) most likely belong to GPCRs that cannot bind the $\mathrm{Na}^{+}$ion. Presence of other $\mathrm{Na}^{+}$ligands 673 in many such sequences suggests that they could have lost their $\mathrm{Na}^{+}$binding capability in the 674 course of their evolution. Loss of $\mathrm{Na}^{+}$binding in the course of GPCR evolution would not necessarily lead to the loss of function; the ability to shift between the active and inactive conformation in response to agonist binding could still be retained. Those residues that appear to form the mechanistic core of the coupling/activating mechanism in GPCRs are mostly conserved also in those GPCRs lacking a counterpart of Asp 2.50. Even without a 679 bound $\mathrm{Na}^{+}$ion, a GPCR could be driven by voltage if its activation is coupled with proton 680 translocation across the membrane [89], e.g. via former $\mathrm{Na}^{+}$ligands. However, in the absence 681 of a $\mathrm{Na}^{+}$-binding site, such GPCRs would be unable to (i) suppress the noise by binding a $\mathrm{Na}^{+}$ 682 ion, (ii) exploit the concentration gradient of $\mathrm{Na}^{+}$ions for increasing their sensitivity and (iii)

683 boost their selectivity by specifically amplifying the signal in response to endogenous 684 agonists. 

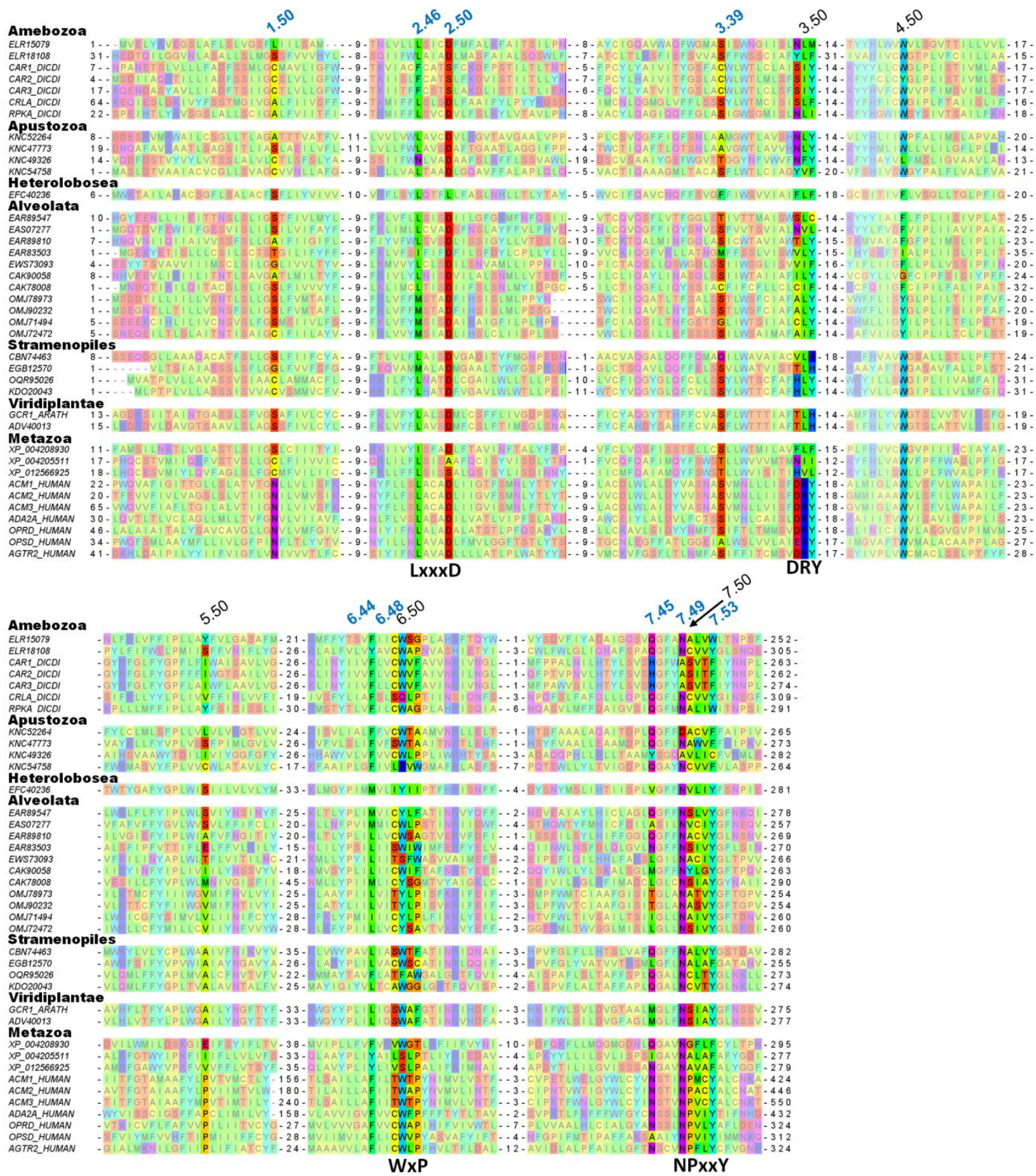

Figure 6. Alignment of diverse GPCRs with human class A GPCR. The top line shows BallesterosWeinstein numbering of the residues [17, 18] as given in GPCRdb [67] for the Class A GPCRs. Generic numbers of residues involved in the $\mathrm{Na}^{+}$ion binding pocket are shown in blue. Sequences are listed under their GenBank, UniProt or RefSeq accessions and are as follows: Amoebozoa: phosphatidylinositol 4-phosphate 5kinase protein from Acanthamoeba castellanii (GenBank: ELR15079); cAMP receptor protein from Acanthamoeba castellanii (GenBank: ELR18108); cAMP receptor 1 from Dictyostelium discoideum (UniProt: CAR1_DICDI); cAMP receptor 2 from Dictyostelium discoideum (UniProt: CAR2_DICDI); cAMP receptor 3 from Dictyostelium discoideum (UniProt: CAR3_DICDI); cAMP receptor-like protein from Dictyostelium discoideum (UniProt: CRLA_DICDI), and G-protein-coupled receptor family protein from Dictyostelium discoideum (UniProt: RPKA_DICDI). Apustozoa: hypothetical protein AMSG_01092 from Thecamonas trahens (GenBank: KNC52264); hypothetical protein AMSG_04000 from Thecamonas trahens (GenBank: KNC47773); hypothetical protein AMSG_02398 from Thecamonas trahens (GenBank: KNC56428); PPK-1 protein from Thecamonas trahens (GenBank: KNC49326); hypothetical protein AMSG_01609 from Thecamonas trahens (GenBank: KNC54758). Heterolobosea: predicted protein NAEGRDRAFT_72027 from Naegleria gruberi (GenBank: EFC40236). Alveolata: G protein coupled glucose receptor from Tetrahymena thermophila (GenBank: EAR89547); 7TM secretin family protein from Tetrahymena thermophila (GenBank: 
EAS07277); 7TM secretin family protein from Tetrahymena thermophila (GenBank: EAR89810); G protein coupled glucose receptor from Tetrahymena thermophila (GenBank: EAR83503); cAMP receptor from Tetrahymena thermophila (GenBank: EWS73093); unnamed protein product from Paramecium tetraurelia (GenBank: CAK90058); hypothetical protein from Paramecium tetraurelia (Genbank: CAK78008); hypothetical protein SteCoe_21100 from Stentor coeruleus (GenBank: OMJ78973); hypothetical protein SteCoe_30276 from Stentor coeruleus (GenBank: OMJ71494); hypothetical protein SteCoe_7430 from Stentor coeruleus (GenBank: OMJ90232); hypothetical protein SteCoe_29065 from Stentor coeruleus (GenBank: OMJ72472). Stramenopiles: G-protein coupled receptor from Ectocarpus siliculosus (GenBank: CBN74463); hypothetical protein AURANDRAFT_4432 from Aureococcus anophagefferens, partial (GenBank: EGB12570); hypothetical protein ACHHYP_00504 from Achlya hypogyna (GanBank: OQR95026); hypothetical protein SPRG_14191 from Saprolegnia parasitica (GenBank: KDO20043). Viridiplantae: Gprotein coupled receptor 1 from Arabidopsis thaliana (UniProt: GCR1_ARATH); G protein coupled receptor from Oryza sativa (GenBank: ADV40013). Metazoa: predicted probable G-protein coupled receptor 157 from Hydra vulgaris, partial (NCBI RefSeq: XP_004208930); predicted cAMP receptor-like protein A from Hydra vulgaris (NCBI RefSeq: XP_004205511); predicted G-protein coupled receptor 1-like protein from Hydra vulgaris (NCBI RefSeq: XP_012566925); human muscarinic acetylcholine receptor $\mathrm{M}_{1}$ (UniProt: ACM1_HUMAN); human muscarinic acetylcholine receptor $\mathrm{M}_{3}$ (UniProt: ACM3_HUMAN); human $\alpha_{2 \mathrm{~A}}$ adrenergic receptor (UniProt: ADA2A_HUMAN); human $\delta$-type opioid receptor (UniProt: OPRD_HUMAN); human visual rhodopsin (UniProt: OPSD_HUMAN).

The existence of both $\mathrm{Na}^{+}$-dependent and $\mathrm{Na}^{+}$-independent GPCRs deserves comparison with rotary ATP synthases, which can be driven either by protons or $\mathrm{Na}^{+}$ions [90]. While $\mathrm{Na}^{+}-$ translocating ATP synthases are found only in some, mostly anaerobic prokaryotes [91], a comparative analysis has indicated their evolutionary primacy [79]. Apparently, in most lineages, the ability to bind and translocate $\mathrm{Na}^{+}$ions got lost; these enzymes, however, retained the ability to translocate protons, which became particularly beneficial after the oxygenation of atmosphere [92]. As already mentioned, holding a $\mathrm{Na}^{+}$ion in the middle of the membrane is structurally rather demanding. Therefore, it is tempting to speculate that more $\mathrm{Na}^{+}$-dependent GPCRs would be seen in organisms that need particularly sensitive and selective receptors for the active exploration of their environment. Indeed, $\mathrm{Na}^{+}$-dependent GPCRs are abundant not only in mammalian genomes, but also in genomes of primitive organisms known for their active behavior, such as free swimming, single-celled ciliates Tetrahymena, Paramecium, or Stentor (Fig. 6). For instance, the genome of Stentor coeruleus contains dozens of GPCR-encoding genes with a full set of $\mathrm{Na}^{+}$ligands.

The Ballesteros-Weinstein nomenclature $[17,18]$ used in this work attributes the index "50" to the amino acid residue that is the most conserved in each helix among class A GPCRs. Comparison of Table 3 with the multiple alignment in Fig. 6 shows that the " $50^{\text {th }}$ residues, while strictly conserved among class A GPCRs, are often not conserved within a broader set of $\mathrm{Na}^{+}$-binding GPCRs. Proline residues 5.50, 6.50 and 7.50, which are strictly conserved within class A GPCRs, are not conserved in receptors of primitive organisms (Fig. 6). It appears that the acquisition of additional proline residues in transmembrane helices could contribute to the success and proliferation of class A GPCRs. These proline residues could 
746 form the mechanistic scaffold of class A GPCRs, stabilize the protein fold and serve as pivots upon receptor activation. The existence of such proline scaffold would relieve the steric constrains on other residues and make class A GPCRs more prone to mutations and, hence, more evolutionarily adaptable.

750 In sum, $\mathrm{Na}^{+}$-dependent GPCRs, after their emergence in primitive eukaryotes, could be finetuned by successive mutations to perform diverse signaling functions. Those mutations would affect their sensitivity, signal-to-noise ratio, chemical selectivity etc. Furthermore, mutations could affect even the voltage/current profiles (where current corresponds to the signal propagation) and determine whether the particular receptor would be sensitized by membrane potential (as the majority of studied GPCRs, see Fig. 3A, 3B and Table S1) or hemmed by it (such as $\mathrm{M}_{1}$ receptor, see Fig. $3 \mathrm{C}$ and Table $\mathrm{S} 1$ ).

\section{Conclusions}

$759 \mathrm{Na}^{+}$-binding GPCRs are splendid molecular sensors that utilize the energy of the 760 transmembrane sodium potential to increase their (i) sensitivity; (ii) signal-to-noise ratio, and 761 (iii) chemical selectivity. The gift of harnessing energy, in conjunction with high adaptability, 762 might explain the presence of about 700 class A GPCR-coding genes in the human genome.

\section{Methods}

\section{Model of $\mathrm{Na}^{+}$translocation by class A GPCRs}

766 Here we present the solution of the model of GPCR activation. The model implies two possible operation modes differing in the $\mathrm{Na}^{+}$ion behavior upon the receptor activation: in the carrier-on mode 1, the cation barges through the membrane into the cytoplasm, while in the carrier-off mode 2 the cation returns into the extracellular space. In each mode, the system is characterized by 8 possible states of the receptor (Fig. 2) whose probabilities are defined as $\mathrm{P}_{1}, \ldots, \mathrm{P}_{8}$ (Table 4). 
774 Table 4. Probability coefficients for the model of GPCR activation

775

776

777

778

779

780

781

782

783

784

785

786

787

788

789

790

791

792

793

794

795

796

797

\begin{tabular}{|l|l|l|}
\hline Receptor state & Probability & Relative probabilities $(l)$ \\
\hline Inactive receptor & $\mathrm{P}_{1}$ & 1 \\
\hline Inactive receptor with $\mathrm{Na}$ & $\mathrm{P}_{2}$ & $\mathrm{M} \cdot[\mathrm{Na}]^{\text {out }}$ \\
\hline Inactive receptor with agonist & $\mathrm{P}_{3}$ & $\mathrm{~N} \cdot[\mathrm{A}]$ \\
\hline Inactive receptor with agonist and $\mathrm{Na}$ & $\mathrm{P}_{4}$ & $\gamma \cdot \mathrm{M}[\mathrm{Na}]^{\text {out }} \cdot \mathrm{N} \cdot[\mathrm{A}]$ \\
\hline Active receptor & $\mathrm{P}_{5}$ & $\mathrm{~F}_{\text {model }} \mathrm{L}^{a}$ \\
\hline Active receptor with Na & $\mathrm{P}_{6}$ & $\alpha \cdot \mathrm{L} \cdot \mathrm{M} \cdot[\mathrm{Na}]^{\text {model }}$ \\
\hline Active receptor with agonist & $\mathrm{P}_{7}$ & $\beta \cdot \mathrm{L} \cdot \mathrm{N} \cdot[\mathrm{A}]$ \\
\hline Active receptor with agonist and Na & $\mathrm{P}_{8}$ & $\alpha \cdot \beta \cdot \gamma \cdot \delta \cdot \mathrm{L} \cdot \mathrm{M} \cdot[\mathrm{Na}]^{\text {model }} \cdot \mathrm{N} \cdot[\mathrm{A}]$ \\
\hline
\end{tabular}

Here, $[\mathrm{Na}]^{\text {model }}$ is the $\mathrm{Na}$ concentration available for the receptor in the active state: $[\mathrm{Na}]^{\text {in }}$ in the carrier-on mode and $[\mathrm{Na}]^{\text {out }}$ in the carrier-off mode. $\mathrm{F}_{\text {model }}$ is the electrostatic term of $\mathrm{Na}^{+}$ ion translocation, which is equal to $F_{2}$ (see Eq. 2) in the carrier-on mode and equal to $F_{1}$ (see Eq. 1) in the carrier-off mode. The forward and backward transitions between the states $m$ and $n$ occur at different rates $l_{1 n}$ and $l_{2 m}$; the transitions between the inactive (R) and active $\left(\mathrm{R}^{*}\right)$ states of the receptor are the slowest in the system. The principle of detailed balance was applied separately to all inactive and all active receptor states, whereas the transitions between active and inactive states are treated as thermodynamically nonequilibrium. In the stationary state, the cumulative forward and backward transition probabilities between active and all inactive states match each other:

$$
l_{11} P_{1}+l_{12} P_{2}+l_{13} P_{3}+l_{14} P_{4}=l_{25} P_{5}+l_{26} P_{6}+l_{27} P_{7}+l_{28} P_{8}
$$

where probabilities $\mathrm{P}_{1-4}$ correspond to all inactive states, $\mathrm{P}_{5-8}$ - to all active states; $l_{1 m}$ and $l_{2 n}$ are the respective transition rate constants (see Table 1). The transition rate constants are not independent, they satisfy the thermodynamic relationship $k_{\text {forward }} / k_{\text {back }}=\mathrm{e}^{-\Delta \mathrm{G} / \mathrm{RT}}$, so the latter equation can be rewritten as following:

$$
l_{1}\left[P_{1}+\alpha^{1 / 2} P_{2}+\beta^{1 / 2} P_{3}+(\alpha \beta \delta)^{1 / 2} P_{4}\right]=l_{2}\left[P_{5}+\alpha^{-1 / 2} P_{6}+\beta^{-1 / 2} P_{7}+(\alpha \beta \delta)^{-1 / 2} P_{8}\right]
$$

where $l_{1}=l_{15}$ and $l_{2}=l_{25}$. The effect of the membrane potential on cation translocation was accounted for the equilibrium constants of $\mathrm{Na}^{+}$binding in both active 
$\left.798 F_{1}=\exp [\theta \Delta \psi F / R T]\right)$ and inactive $\left(F_{2}=\exp [(1-\theta) \Delta \psi F / R T]\right)$ states, where $\theta$ is the

799 depth of the $\mathrm{Na}^{+}$-binding site, $\Delta \psi$ is the transmembrane electric potential , and $F$ is the

800 Faraday constant. This leads to the relation:

801

$P_{5}=\xi \cdot L \cdot P_{1}$

802 where

803

804

805

806

807

808

809

810

811

812

813

814

815

816

817

818

819

820

821

822

823

824

825

826

827

$\xi=\frac{1+\alpha^{1 / 2} F_{1} X_{o u t}+\beta^{1 / 2} Y+(\alpha \beta \delta)^{1 / 2} F_{1} \gamma X_{o u t} Y}{1+\alpha^{1 / 2} F_{2} X_{\text {in }}+\beta^{1 / 2} Y+(\alpha \beta \delta)^{1 / 2} F_{2} \gamma X_{\text {in }} Y}$

and $L=l_{1} / l_{2}$. In the latter equation we have used

$$
X_{\text {in/out }}=M \cdot\left[\mathrm{Na}^{+}\right]_{\text {in/out }}
$$

and $\quad, \quad Y=N \cdot[$ ago\$ $\$ 5 t]$ respectively.

To these equations we must add the probabilities normalization requirement:

$$
\sum_{i=1 . .8} P_{i}=1
$$

and resulting set of equations provides a solution to our model.

Suggested models for GPCR activation were implemented as Matlab R2017a functions [93]. Experimental data were obtained from respective publications and fitted with model functions using the Matlab' "lsqcurvefit" function. During the fit, the allosteric coefficients $\alpha$ $\delta$ and the depth of the $\mathrm{Na}^{+}$-binding site were kept constant. The goal was to find coefficients $\mathrm{M}$ ( $\mathrm{Na}^{+}$-binding constant) and $\mathrm{N}$ (agonist-binding constant) that provided the best fit of the experimental data (two sets of data points obtained at different membrane potential) with the two model curves calculated with identical parameters except for the membrane potential values.

\section{Structure analysis}

Structure superposition and visualization were performed with PyMol v 1.7 [72] and YASARA [94]. Structure analyses were performed with the WHAT IF [95] subset of the YASARA Twinset. Cavities and caves were calculated using the method by Voorintholt et al [96] with a spherical probe of the $1.4 \AA$ radius. These were visualized using a $1 \AA$ resolution grid. Structures were superposed using the method of Vriend and Sander [97]. Rotamer distributions were calculated using the method of Chinea et al. [70]. Briefly, the rotamer distribution software searches the PDB for stretches of five residues that (i) have a very similar backbone as observed in the local structure and (ii) have the same middle residue as 
the local structure. The obtained database stretches is then superposed on the local structure, but only the side chain of the middle residue is shown.

830

\section{Acknowledgements}

832 The authors would like to thank Profs. V. Katritch, H.-J. Steinhoff and H. Vogel for 833 encouragement and very useful discussions. Helpful advises of Dr. N.P. Isaev are greatly 834 appreciated. The calculations were done using the equipment of the shared research facilities 835 of HPC computing resources at Lomonosov Moscow State University supported by its 836 Development Program. This study was supported by the Deutsche Forschungsgemeinschaft, 837 Federal Ministry of Education and Research of Germany, the EvoCell Program of the 838 Osnabrueck University (AYM), the Ostpartnerschaftenprogramm of the German Academic 839 Exchange Service (DAAD), the Russian Government contract (AAAA-A19-119012890064840 7), and the 14-50-00029 grant from the Russian Science Foundation (DNS). MYG is 841 supported by the Intramural Research Program of the NIH at the National Library of 842 Medicine.

\section{Author contributions}

844 AYM designed the study. AYM, DAC and DNS developed the model. DNS calculated the 845 model and fitted experimental data. DNS, AYM, MYG and GV performed the structural 846 analysis. DNS, MYG and AYM performed the evolutionary analysis. DNS, DAC, MYG, $847 \mathrm{GV}$ and AYM wrote the paper.

848

849 Competing interests

850 Authors confirm that there have been no involvements that might raise the question of bias in 851 the work reported or in the conclusions, implications, or opinions stated.

852 


\section{References}

[1] V. Katritch, V. Cherezov, R.C. Stevens, Structure-function of the G protein-coupled receptor superfamily, Annu Rev Pharmacol Toxicol, 53 (2013) 531-556.

[2] A. Manglik, T.H. Kim, M. Masureel, C. Altenbach, Z. Yang, D. Hilger, M.T. Lerch, T.S. Kobilka, F.S. Thian, W.L. Hubbell, R.S. Prosser, B.K. Kobilka, Structural insights into the dynamic process of beta2-adrenergic receptor signaling, Cell, 161 (2015) 1101-1111.

[3] D.G. Isom, H.G. Dohlman, Buried ionizable networks are an ancient hallmark of G proteincoupled receptor activation, Proc. Natl. Acad. Sci. USA, 112 (2015) 5702-5707.

[4] D. Wacker, R.C. Stevens, B.L. Roth, How Ligands Illuminate GPCR Molecular Pharmacology, Cell, 170 (2017) 414-427.

[5] A. Krishnan, M.S. Almen, R. Fredriksson, H.B. Schioth, The origin of GPCRs: identification of mammalian like Rhodopsin, Adhesion, Glutamate and Frizzled GPCRs in fungi, PLoS One, 7 (2012) e29817.

[6] K.J. Nordstrom, M. Sallman Almen, M.M. Edstam, R. Fredriksson, H.B. Schioth, Independent HHsearch, Needleman--Wunsch-based, and motif analyses reveal the overall hierarchy for most of the G protein-coupled receptor families, Molecular biology and evolution, 28 (2011) 24712480 .

[7] D.N. Shalaeva, M.Y. Galperin, A.Y. Mulkidjanian, Eukaryotic G protein-coupled receptors as descendants of prokaryotic sodium-translocating rhodopsins, Biol. Direct, 10 (2015) 63.

[8] K. Palczewski, T. Kumasaka, T. Hori, C.A. Behnke, H. Motoshima, B.A. Fox, I. Le Trong, D.C. Teller, T. Okada, R.E. Stenkamp, M. Yamamoto, M. Miyano, Crystal structure of rhodopsin: A G protein-coupled receptor, Science, 289 (2000) 739-745.

[9] J.H. Park, P. Scheerer, K.P. Hofmann, H.W. Choe, O.P. Ernst, Crystal structure of the ligand-free G-protein-coupled receptor opsin, Nature, 454 (2008) 183-187.

[10] P. Scheerer, J.H. Park, P.W. Hildebrand, Y.J. Kim, N. Krauss, H.W. Choe, K.P. Hofmann, O.P. Ernst, Crystal structure of opsin in its G-protein-interacting conformation, Nature, 455 (2008) 497-502.

[11] B. Kobilka, G.F. Schertler, New G-protein-coupled receptor crystal structures: insights and limitations, Trends Pharmacol. Sci., 29 (2008) 79-83.

[12] W. Liu, E. Chun, A.A. Thompson, P. Chubukov, F. Xu, V. Katritch, G.W. Han, C.B. Roth, L.H. Heitman, I.J. AP, V. Cherezov, R.C. Stevens, Structural basis for allosteric regulation of GPCRs by sodium ions, Science, 337 (2012) 232-236.

[13] A.C. Kruse, A.M. Ring, A. Manglik, J. Hu, K. Hu, K. Eitel, H. Hubner, E. Pardon, C. Valant, P.M. Sexton, A. Christopoulos, C.C. Felder, P. Gmeiner, J. Steyaert, W.I. Weis, K.C. Garcia, J. Wess, B.K. Kobilka, Activation and allosteric modulation of a muscarinic acetylcholine receptor, Nature, 504 (2013) 101-106.

[14] K. Haga, A.C. Kruse, H. Asada, T. Yurugi-Kobayashi, M. Shiroishi, C. Zhang, W.I. Weis, T. Okada, B.K. Kobilka, T. Haga, T. Kobayashi, Structure of the human M2 muscarinic acetylcholine receptor bound to an antagonist, Nature, 482 (2012) 547-U147.

[15] G. Fenalti, P.M. Giguere, V. Katritch, X.P. Huang, A.A. Thompson, V. Cherezov, B.L. Roth, R.C. Stevens, Molecular control of delta-opioid receptor signalling, Nature, 506 (2014) 191-196.

[16] J.L. Miller-Gallacher, R. Nehme, T. Warne, P.C. Edwards, G.F. Schertler, A.G. Leslie, C.G. Tate, The 2.1 A resolution structure of cyanopindolol-bound beta1-adrenoceptor identifies an intramembrane $\mathrm{Na}+$ ion that stabilises the ligand-free receptor, PLoS One, 9 (2014) e92727. 
[17] J.A. Ballesteros, H. Weinstein, Integrated methods for the construction of three-dimensional models and computational probing of structure-function relations in $\mathrm{G}$ protein-coupled receptors, in: Methods in Neurosciences, Elsevier, 1995, pp. 366-428.

[18] V. Isberg, C. de Graaf, A. Bortolato, V. Cherezov, V. Katritch, F.H. Marshall, S. Mordalski, J.P. Pin, R.C. Stevens, G. Vriend, D.E. Gloriam, Generic GPCR residue numbers - aligning topology maps while minding the gaps, Trends Pharmacol. Sci., 36 (2015) 22-31.

[19] B. Knierim, K.P. Hofmann, W. Gartner, W.L. Hubbell, O.P. Ernst, Rhodopsin and 9-demethylretinal analog: effect of a partial agonist on displacement of transmembrane helix 6 in class A G protein-coupled receptors, J. Biol. Chem., 283 (2008) 4967-4974.

[20] B. Knierim, K.P. Hofmann, O.P. Ernst, W.L. Hubbell, Sequence of late molecular events in the activation of rhodopsin, Proc. Natl. Acad. Sci. USA, 104 (2007) 20290-20295.

[21] L. Shi, G. Liapakis, R. Xu, F. Guarnieri, J.A. Ballesteros, J.A. Javitch, Beta2 adrenergic receptor activation. Modulation of the proline kink in transmembrane 6 by a rotamer toggle switch, J Biol Chem, 277 (2002) 40989-40996.

[22] M.T. Eddy, M.Y. Lee, Z.G. Gao, K.L. White, T. Didenko, R. Horst, M. Audet, P. Stanczak, K.M. McClary, G.W. Han, K.A. Jacobson, R.C. Stevens, K. Wuthrich, allosteric coupling of drug binding and intracellular signaling in the $\mathrm{A}_{2 \mathrm{~A}}$ adenosine receptor, Cell, 172 (2018) 68-80 e12.

[23] S. Yuan, K. Palczewski, Q. Peng, M. Kolinski, H. Vogel, S. Filipek, The mechanism of ligandinduced activation or inhibition of mu- and kappa-opioid receptors, Angew Chem Int Ed Engl, 54 (2015) 7560-7563.

[24] S. Yuan, Z. Hu, S. Filipek, H. Vogel, W246(6.48) opens a gate for a continuous intrinsic water pathway during activation of the adenosine $A_{2 \mathrm{~A}}$ receptor, Angew Chem Int Ed Engl, 54 (2015) 556-559.

[25] S. Yuan, H. Vogel, S. Filipek, The role of water and sodium ions in the activation of the muopioid receptor, Angew Chem Int Ed Engl, 52 (2013) 10112-10115.

[26] V. Katritch, G. Fenalti, E.E. Abola, B.L. Roth, V. Cherezov, R.C. Stevens, Allosteric sodium in class A GPCR signaling, Trends Biochem. Sci., 39 (2014) 233-244.

[27] A. Massink, H. Gutierrez-de-Teran, E.B. Lenselink, N.V. Ortiz Zacarias, L. Xia, L.H. Heitman, V. Katritch, R.C. Stevens, A.P. IJzerman, Sodium ion binding pocket mutations and adenosine $\mathrm{A}_{2 \mathrm{~A}}$ receptor function, Mol. Pharmacol., 87 (2015) 305-313.

[28] K.L. White, M.T. Eddy, Z.G. Gao, G.W. Han, T. Lian, A. Deary, N. Patel, K.A. Jacobson, V. Katritch, R.C. Stevens, Structural connection between activation microswitch and allosteric sodium site in gpcr signaling, Structure, 26 (2018) 259-269 e255.

[29] M.A. Lomize, I.D. Pogozheva, H. Joo, H.I. Mosberg, A.L. Lomize, OPM database and PPM web server: resources for positioning of proteins in membranes, Nucleic Acids Res., 40 (2012) D370376.

[30] C.B. Pert, G. Pasternak, S.H. Snyder, Opiate agonists and antagonists discriminated by receptor binding in brain, Science, 182 (1973) 1359-1361.

[31] D.A. Horstman, S. Brandon, A.L. Wilson, C.A. Guyer, E.J. Cragoe, Jr., L.E. Limbird, An aspartate conserved among G-protein receptors confers allosteric regulation of alpha 2-adrenergic receptors by sodium, J. Biol. Chem., 265 (1990) 21590-21595.

[32] K.E. Livingston, J.R. Traynor, Disruption of the $\mathrm{Na}^{+}$ion binding site as a mechanism for positive allosteric modulation of the mu-opioid receptor, Proc. Natl. Acad. Sci. USA, 111 (2014) 1836918374.

[33] Y. Shang, V. LeRouzic, S. Schneider, P. Bisignano, G.W. Pasternak, M. Filizola, Mechanistic insights into the allosteric modulation of opioid receptors by sodium ions, Biochemistry, 53 (2014) 5140-5149. 
[34] S.G. Rasmussen, H.J. Choi, J.J. Fung, E. Pardon, P. Casarosa, P.S. Chae, B.T. Devree, D.M. Rosenbaum, F.S. Thian, T.S. Kobilka, A. Schnapp, I. Konetzki, R.K. Sunahara, S.H. Gellman, A. Pautsch, J. Steyaert, W.I. Weis, B.K. Kobilka, Structure of a nanobody-stabilized active state of the beta(2) adrenoceptor, Nature, 469 (2011) 175-180.

[35] W. Huang, A. Manglik, A.J. Venkatakrishnan, T. Laeremans, E.N. Feinberg, A.L. Sanborn, H.E. Kato, K.E. Livingston, T.S. Thorsen, R.C. Kling, S. Granier, P. Gmeiner, S.M. Husbands, J.R. Traynor, W.I. Weis, J. Steyaert, R.O. Dror, B.K. Kobilka, Structural insights into micro-opioid receptor activation, Nature, 524 (2015) 315-321.

[36] S. Yuan, S. Filipek, K. Palczewski, H. Vogel, Activation of G-protein-coupled receptors correlates with the formation of a continuous internal water pathway, Nat Commun, 5 (2014) 4733.

[37] O.N. Vickery, C.A. Carvalheda, S.A. Zaidi, A.V. Pisliakov, V. Katritch, U. Zachariae, Intracellular Transfer of $\mathrm{Na}(+)$ in an Active-State G-Protein-Coupled Receptor, Structure, 26 (2018) 171-180 e172.

[38] M.P. Mahaut-Smith, J. Martinez-Pinna, I.S. Gurung, A role for membrane potential in regulating GPCRs?, Trends Pharmacol. Sci., 29 (2008) 421-429.

[39] O.N. Vickery, J.P. Machtens, U. Zachariae, Membrane potentials regulating GPCRs: insights from experiments and molecular dynamics simulations, Curr Opin Pharmacol, 30 (2016) 44-50.

[40] M. Wikstrom, K. Krab, M. Saraste, Proton-translocating cytochrome complexes, Annu Rev Biochem, 50 (1981) 623-655.

[41] P. Leff, The two-state model of receptor activation, Trends Pharmacol. Sci., 16 (1995) 89-97.

[42] D.A. Hall, Modeling the functional effects of allosteric modulators at pharmacological receptors: an extension of the two-state model of receptor activation, Mol Pharmacol, 58 (2000) 1412-1423.

[43] R.A. Copeland, The drug-target residence time model: a 10-year retrospective, Nat Rev Drug Discov, 15 (2016) 87-95.

[44] R.A. Copeland, Drug-target residence time, in: G.M. Keseru (Ed.) Thermodynamics and Kinetics of Drug Binding, Wiley-VCH Verlag GmbH, 2015, pp. 157-167.

[45] R. Lamichhane, J.J. Liu, G. Pljevaljcic, K.L. White, E. van der Schans, V. Katritch, R.C. Stevens, K. Wuthrich, D.P. Millar, Single-molecule view of basal activity and activation mechanisms of the G protein-coupled receptor beta2AR, Proc Natl Acad Sci U S A, 112 (2015) 14254-14259.

[46] L. Ye, N. Van Eps, M. Zimmer, O.P. Ernst, R.S. Prosser, Activation of the $A_{2 \mathrm{~A}}$ adenosine Gprotein-coupled receptor by conformational selection, Nature, 533 (2016) 265-268.

[47] L. Susac, M.T. Eddy, T. Didenko, R.C. Stevens, K. Wuthrich, $A_{2 A}$ adenosine receptor functional states characterized by (19)F-NMR, Proc Natl Acad Sci U S A, (2018).

[48] S. Arnis, K.P. Hofmann, Two different forms of metarhodopsin II: Schiff base deprotonation precedes proton uptake and signaling state, Proc. Natl. Acad. Sci. USA, 90 (1993) 7849-7853.

[49] A. Rinne, J.C. Mobarec, M. Mahaut-Smith, P. Kolb, M. Bunemann, The mode of agonist binding to a $\mathrm{G}$ protein-coupled receptor switches the effect that voltage changes have on signaling, Sci Signal, 8 (2015).

[50] A. Rinne, A. Birk, M. Bunemann, Voltage regulates adrenergic receptor function, Proc. Natl. Acad. Sci. USA, 110 (2013) 1536-1541.

[51] Y. Ben-Chaim, O. Tour, N. Dascal, I. Parnas, H. Parnas, The M2 muscarinic G-protein-coupled receptor is voltage-sensitive, J. Biol. Chem., 278 (2003) 22482-22491.

[52] Y. Ben-Chaim, B. Chanda, N. Dascal, F. Bezanilla, I. Parnas, H. Parnas, Movement of 'gating charge' is coupled to ligand binding in a G-protein-coupled receptor, Nature, 444 (2006) 106109. 
[53] P.G. Strange, Agonist binding, agonist affinity and agonist efficacy at G protein-coupled receptors, Br J Pharmacol, 153 (2008) 1353-1363.

[54] O. Barchad-Avitzur, M.F. Priest, N. Dekel, F. Bezanilla, H. Parnas, Y. Ben-Chaim, A novel voltage sensor in the orthosteric binding site of the M2 muscarinic receptor, Biophys. J., 111 (2016) 1396-1408.

[55] P. Mitchell, Chemiosmotic coupling in oxidative and photosynthetic phosphorylation, Biol Rev Camb Philos Soc, 41 (1966) 445-502.

[56] P. Dimroth, Bacterial energy transductions coupled to sodium ions, Res Microbiol, 141 (1990) 332-336.

[57] R.A. Navarro-Polanco, E.G. Moreno Galindo, T. Ferrer-Villada, M. Arias, J.R. Rigby, J.A. Sanchez-Chapula, M. Tristani-Firouzi, Conformational changes in the M2 muscarinic receptor induced by membrane voltage and agonist binding, J Physiol, 589 (2011) 1741-1753.

[58] E.G. Moreno-Galindo, J. Alamilla, J.A. Sanchez-Chapula, M. Tristani-Firouzi, R.A. NavarroPolanco, The agonist-specific voltage dependence of M2 muscarinic receptors modulates the deactivation of the acetylcholine-gated K(+) current (I KACh), Pflugers Arch, 468 (2016) 12071214.

[59] K. Sahlholm, D. Marcellino, J. Nilsson, K. Fuxe, P. Arhem, Voltage-sensitivity at the human dopamine D2S receptor is agonist-specific, Biochem. Biophys. Res. Commun., 377 (2008) 12161221.

[60] K. Sahlholm, O. Barchad-Avitzur, D. Marcellino, M. Gomez-Soler, K. Fuxe, F. Ciruela, P. Arhem, Agonist-specific voltage sensitivity at the dopamine D2S receptor--molecular determinants and relevance to therapeutic ligands, Neuropharmacology, 61 (2011) 937-949.

[61] K. Sahlholm, D. Marcellino, J. Nilsson, K. Fuxe, P. Arhem, Differential voltage-sensitivity of D2-like dopamine receptors, Biochem. Biophys. Res. Commun., 374 (2008) 496-501.

[62] A.C. Kruse, J. Hu, B.K. Kobilka, J. Wess, Muscarinic acetylcholine receptor X-ray structures: potential implications for drug development, Curr Opin Pharmacol, 16 (2014) 24-30.

[63] Y. Ben Chaim, S. Bochnik, I. Parnas, H. Parnas, Voltage affects the dissociation rate constant of the $\mathrm{m} 2$ muscarinic receptor, PLoS One, 8 (2013) e74354.

[64] L. Oliveira, A.C.d.M. Paiva, G. Vriend, A common motif in G-protein-coupled seven transmembrane helix receptors, J Comput Aid Mol Des, 7 (1993) 649-658.

[65] R. Nygaard, T.M. Frimurer, B. Holst, M.M. Rosenkilde, T.W. Schwartz, Ligand binding and micro-switches in 7TM receptor structures, Trends Pharmacol. Sci., 30 (2009) 249-259.

[66] B. Trzaskowski, D. Latek, S. Yuan, U. Ghoshdastider, A. Debinski, S. Filipek, Action of molecular switches in GPCRs--theoretical and experimental studies, Curr Med Chem, 19 (2012) 1090-1109.

[67] V. Isberg, B. Vroling, R. van der Kant, K. Li, G. Vriend, D. Gloriam, GPCRDB: an information system for G protein-coupled receptors, Nucleic Acids Res., 42 (2014) D422-D425.

[68] T. Okada, O.P. Ernst, K. Palczewski, K.P. Hofmann, Activation of rhodopsin: new insights from structural and biochemical studies, Trends Biochem. Sci., 26 (2001) 318-324.

[69] B.G. Tehan, A. Bortolato, F.E. Blaney, M.P. Weir, J.S. Mason, Unifying family A GPCR theories of activation, Pharmacol Ther, 143 (2014) 51-60.

[70] G. Chinea, G. Padron, R.W. Hooft, C. Sander, G. Vriend, The use of position-specific rotamers in model building by homology, Proteins-Structure Function and Bioinformatics, 23 (1995) 415421.

[71] R.P. Joosten, F. Long, G.N. Murshudov, A. Perrakis, The PDB_REDO server for macromolecular structure model optimization, IUCrJ, 1 (2014) 213-220. 
[72] The PyMOL Molecular Graphics System, Version 1.7.2.1, in, Schrödinger, LLC., 2010.

1039

1040

1041

1042

1043

1044

1045

1046

1047

1048

1049

1050

1051

1052

1053

1054

1055

1056

1057

1058

1059

1060

1061

1062

1063

1064

1065

1066

1067

1068

1069

1070

1071

1072

1073

1074

1075

1076

1077

1078

1079

1080

1081

1082

1083

1084

[73] I. Gushchin, V. Shevchenko, V. Polovinkin, K. Kovalev, A. Alekseev, E. Round, V. Borshchevskiy, T. Balandin, A. Popov, T. Gensch, C. Fahlke, C. Bamann, D. Willbold, G. Buldt, E. Bamberg, V. Gordeliy, Crystal structure of a light-driven sodium pump, Nat Struct Mol Biol, 22 (2015) 390-395.

[74] H.E. Kato, K. Inoue, R. Abe-Yoshizumi, Y. Kato, H. Ono, M. Konno, S. Hososhima, T. Ishizuka, M.R. Hoque, H. Kunitomo, J. Ito, S. Yoshizawa, K. Yamashita, M. Takemoto, T. Nishizawa, R. Taniguchi, K. Kogure, A.D. Maturana, Y. Iino, H. Yawo, R. Ishitani, H. Kandori, O. Nureki, Structural basis for $\mathrm{Na}^{+}$transport mechanism by a light-driven $\mathrm{Na}^{+}$pump, Nature, 521 (2015) 4853.

[75] M.S. Bee, E.C. Hulme, Functional analysis of transmembrane domain 2 of the M1 muscarinic acetylcholine receptor, J. Biol. Chem., 282 (2007) 32471-32479.

[76] G. Lebon, T. Warne, P.C. Edwards, K. Bennett, C.J. Langmead, A.G.W. Leslie, C.G. Tate, Agonist-bound adenosine A(2A) receptor structures reveal common features of GPCR activation, Nature, 474 (2011) 521-U154.

[77] J.M. Bibbe, G. Vriend, Motions around conserved structural weak spots determine GPCR activity, submitted, (2019).

[78] A. Warshel, S.T. Russell, Calculations of electrostatic interactions in biological systems and in solutions, Q Rev Biophys, 17 (1984) 283-422.

[79] A.Y. Mulkidjanian, M.Y. Galperin, K.S. Makarova, Y.I. Wolf, E.V. Koonin, Evolutionary primacy of sodium bioenergetics, Biol. Direct, 3 (2008) 13.

[80] T. Meier, A. Krah, P.J. Bond, D. Pogoryelov, K. Diederichs, J.D. Faraldo-Gomez, Complete ioncoordination structure in the rotor ring of $\mathrm{Na}^{+}$-dependent F-ATP synthases, J. Mol. Biol., 391 (2009) 498-507.

[81] G. Kaim, F. Wehrle, U. Gerike, P. Dimroth, Molecular basis for the coupling ion selectivity of F1F0 ATP synthases: probing the liganding groups for $\mathrm{Na}^{+}$and $\mathrm{Li}^{+}$in the $\mathrm{c}$ subunit of the ATP synthase from Propionigenium modestum, Biochemistry, 36 (1997) 9185-9194.

[82] A. Dickey, R. Faller, Examining the contributions of lipid shape and headgroup charge on bilayer behavior, Biophys. J., 95 (2008) 2636-2646.

[83] S. Jo, T. Kim, V.G. Iyer, W. Im, CHARMM-GUI: a web-based graphical user interface for CHARMM, J. Comput. Chem., 29 (2008) 1859-1865.

[84] O. Volkov, K. Kovalev, V. Polovinkin, V. Borshchevskiy, C. Bamann, R. Astashkin, E. Marin, A. Popov, T. Balandin, D. Willbold, G. Buldt, E. Bamberg, V. Gordeliy, Structural insights into ion conduction by channelrhodopsin 2, Science, 358 (2017).

[85] A.A. Wegener, I. Chizhov, M. Engelhard, H.J. Steinhoff, Time-resolved detection of transient movement of helix F in spin-labelled pharaonis sensory rhodopsin II, J. Mol. Biol., 301 (2000) 881-891.

[86] J.P. Klare, E. Bordignon, M. Engelhard, H.J. Steinhoff, Sensory rhodopsin II and bacteriorhodopsin: light activated helix F movement, Photochem. Photobiol. Sci., 3 (2004) 543547.

[87] T. Sattig, C. Rickert, E. Bamberg, H.J. Steinhoff, C. Bamann, Light-induced movement of the transmembrane helix B in channelrhodopsin-2, Angew Chem Int Ed Engl, 52 (2013) 9705-9708.

[88] S.P. Balashov, E.S. Imasheva, A.K. Dioumaev, J.M. Wang, K.H. Jung, J.K. Lanyi, Light-driven $\mathrm{Na}^{+}$pump from Gillisia limnaea: a high-affinity $\mathrm{Na}^{+}$binding site is formed transiently in the photocycle, Biochemistry, 53 (2014) 7549-7561.

[89] X.C. Zhang, C. Cao, Y. Zhou, Y. Zhao, Proton transfer-mediated GPCR activation, Protein Cell, 6 (2015) 12-17. 
[90] P. Dimroth, C. von Ballmoos, T. Meier, Catalytic and mechanical cycles in F-ATP synthases. Fourth in the Cycles Review Series, EMBO Rep, 7 (2006) 276-282.

[91] A.Y. Mulkidjanian, P. Dibrov, M.Y. Galperin, The past and present of sodium energetics: may the sodium-motive force be with you, Biochim. Biophys. Acta, 1777 (2008) 985-992.

[92] D.V. Dibrova, M.Y. Galperin, E.V. Koonin, A.Y. Mulkidjanian, Ancient systems of sodium/potassium homeostasis as predecessors of membrane bioenergetics, Biochemistry (Mosc), 80 (2015) 495-516.

1091

1092

[93] MATLAB and Statistics Toolbox Release 2017a, in, The MathWorks, Inc. , 2017.

[94] E. Krieger, G. Vriend, YASARA View-molecular graphics for all devices-from smartphones to workstations, Bioinformatics, 30 (2014) 2981-2982.

[95] G. Vriend, WHAT IF: a molecular modeling and drug design program, J Mol Graph, 8 (1990) 52-56, 29.

1097

[96] R. Voorintholt, M.T. Kosters, G. Vegter, G. Vriend, W.G. Hol, A very fast program for visualizing protein surfaces, channels and cavities, J Mol Graph, 7 (1989) 243-245.

1099

[97] G. Vriend, C. Sander, Detection of common three-dimensional substructures in proteins, Proteins-Structure Function and Bioinformatics, 11 (1991) 52-58. 